\title{
The role of stem cells in uterine involution
}

\author{
Madelyn K Spooner ${ }^{1}$, Yasser Y Lenis ${ }^{1,3}$, Rachel Watson ${ }^{2}$, Daniela Jaimes ${ }^{4}$ and \\ Amanda L Patterson ${ }^{1,2}$ \\ ${ }^{1}$ Division of Animal Sciences, University of Missouri, Columbia, Missouri, USA, ${ }^{2}$ Department of Obstetrics, \\ Gynecology and Women's Health, University of Missouri, Columbia, Missouri, USA, ${ }^{3}$ Department of Animal \\ Sciences, Faculty of Agricultural Sciences, National University of Colombia, Palmira, Colombia and ${ }^{4}$ Faculty of \\ Agricultural Sciences, University of Applied and Environmental Sciences U.D.C.A, Bogota, Colombia
}

Correspondence should be addressed to A L Patterson; Email: Pattersonama@missouri.edu

\begin{abstract}
Uterine remodeling during pregnancy and repair postpartum are fundamental to the successful propagation of eutherian species. The most drastic remodeling occurs in species with invasively implanting embryos, including humans and mice. During embryo implantation, embryonic trophoblasts breach the epithelium, penetrating into the stroma. Stromal cell decidualization, which is critical for the establishment and maintenance of early pregnancy, occurs throughout the implantation site. Trophoblasts further invade into and remodel uterine spiral arteries, which is necessary for placental formation. The uterus increases in size up to 24-fold, which is largely attributed to myometrial expansion. Uterine changes that occur during pregnancy must then be resolved postpartum. Following parturition, the uterus repairs the remodeled tissue in the process of uterine involution. During involution, the majority of the endometrium is regenerated to replace the tissue that is shed postpartum. The myometrium returns to the pre-gravid state which is thought to occur through apoptosis and autophagy of smooth muscle cells. Although we understand the general process of postpartum uterine involution, the detailed mechanisms, particularly the role of putative stem cells, are poorly understood. This review discusses the evidence for the existence of epithelial, stromal and myometrial stem cells and their role in uterine involution. Gaps in knowledge and areas for future research are also considered. Studies of both postpartum and menstrual uterine repair, which likely involve similar mechanisms, are described under the broad definition of uterine involution. Although the primary focus of this review is human, mouse models are discussed to provide additional information.

Reproduction (2021) 161 R61-R77
\end{abstract}

\section{Overview of uterine physiology}

In the simplest of terms, pregnancy and postpartum involution can be likened to normal physiological damage and repair processes, respectively. During pregnancy, the uterus undergoes dramatic remodeling events including invasion by embryonic trophoblasts, stromal cell decidualization and myometrial hyperplasia and hypertrophy, among others. Although these events are physiologically normal and necessary for pregnancy, they result in physiological 'damage' and loss of many cell types that require regeneration and repair postpartum. Likewise, the menstrual cycle in women is a series of physiological remodeling and repair events, which likely shares similarities with those that occur during pregnancy and postpartum involution. It has long been proposed that due to the extensive remodeling that the uterus undergoes, it likely contains stem cells that function to repopulate the various cell types of the uterus (Gargett 2007). In this section, a brief description of the uterine histoarchitecture of the human and mouse is given. This is followed by discussion of the major events in the menstrual (and estrous) cycle, pregnancy and uterine involution (both menstrual and postpartum). The primary focus of this review is human uterine physiology, however comparisons with mice are included to provide additional insight into uterine remodeling and regeneration.

\section{Uterine histoarchitecture}

Uterine involution has mostly been studied either by histological evaluation of uterine tissue during menstrual repair in humans or using pregnancy and menses-like mouse models. Histologically, the uteri of humans and mice are similar being comprised of three distinguishable tissue layers: (1) the outer-most perimetrium, or serosa, which is contiguous with the broad ligament, (2) the smooth muscle layer, termed the myometrium and (3) the inner-most endometrium (Fig. 1A). In humans, the endometrium is subdivided into the transient functional layer (functionalis; inner two-thirds), which is shed and regenerated throughout the menstrual cycle and the germinal basal layer (basalis; lower one- 


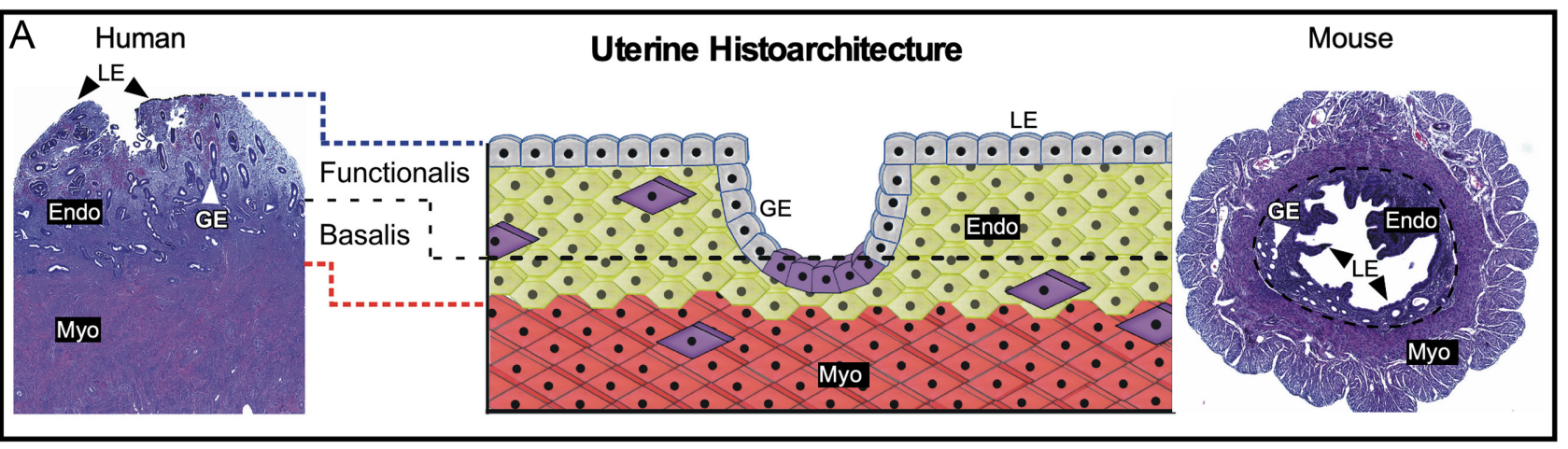

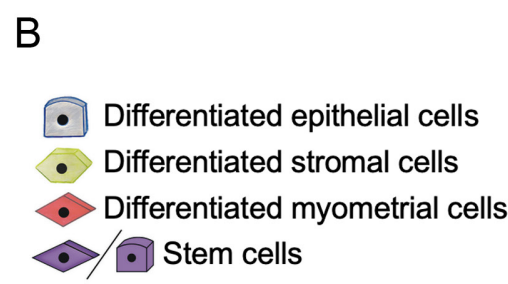

B

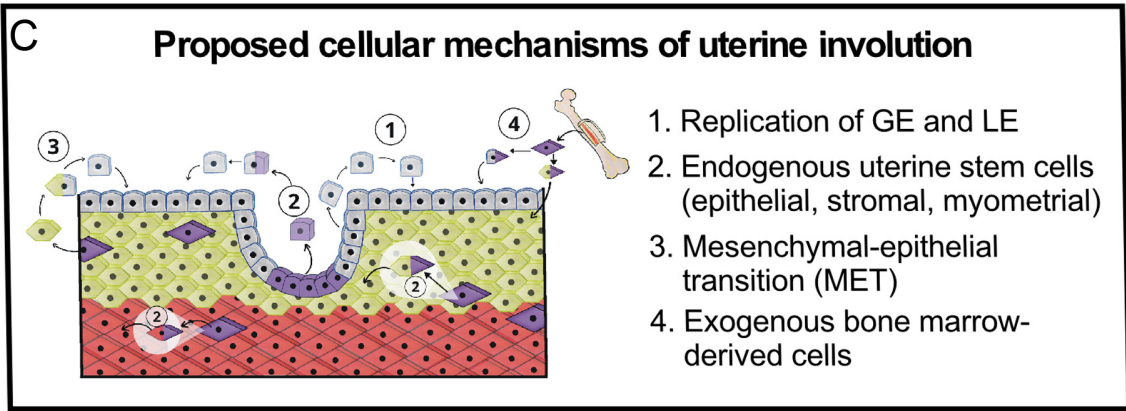

Figure 1 Uterine histoarchitecture and hypothesized mechanisms of uterine involution. (A) Human and mouse histology images show myometrial (Myo) and endometrial (Endo) layers of the uterus. The human endometrium is segmented into the functionalis and basalis, indicated by dashed lines in cartoon/histology images. Both mouse and human uteri contain luminal and glandular epithelial cells (LE and GE, respectively) stromal cells, and myometrial cells. (B) Key of cartoon cells depicted in A and C. (C) Proposed mechanisms of uterine involution include: 1) replication of residual glandular and luminal epithelial cells that escaped desquamation, 2) Endogenous epithelial, stromal and myometrial stem cells, 3) Mesenchymal-epithelial transition (MET) of stromal cells into epithelial cells, and 4) Exogenous bone marrow-derived cells.

third) (Fig. 1A, Human). Mice have similar layers to the functionalis and basalis; however, the 'functional layer' is not shed and regenerated during the estrous cycle but only after pregnancy. The endometrium is predominantly comprised of epithelial and stromal (mesenchymal) cells. The functionalis, which is nearest to the lumen, is lined by a monolayer of luminal epithelium (LE) that also invaginates to form epithelial-lined glands (glandular epithelium, GE). These glands are embedded within the stroma and extend into the basalis down to the myometrium. The myometrium is comprised primarily of smooth muscle and fibroblast cells. In the mouse, but not in the human, the myometrium consists of two distinct layers, the inner circular and outer longitudinal muscularis (Fig. 1A, Mouse). Both the endometrium and myometrium are inundated with blood vessels, lymphatics and immune cells.

\section{Uterine remodeling during the menstrual and estrous cycles}

The menstrual cycle is standardized to 28 days and proceeds in three phases: menses, proliferative and secretory. Ovulation occurs on day (D) 14 and demarcates the proliferative and secretory phases, which correspond to the estrogen $\left(E_{2}\right)$ dominant follicular phase and progesterone $\left(\mathrm{P}_{4}\right)$ dominant luteal phase, respectively, of the ovarian cycle. The first day of menses (menstrual bleeding/shedding) marks the beginning (D1) of the menstrual cycle and occurs due to steroid hormone withdrawal following the demise of the corpus luteum (luteolysis). During menses, desquamation occurs: epithelial, stromal and endothelial cells of the functionalis undergo apoptosis leading to shedding and expulsion of the tissue (Jabbour et al. 2006). With loss of the functionalis, only a small proportion $(\sim 2 \mathrm{~mm})$ of the endometrium, the basalis, remains. Regeneration of the functionalis occurs simultaneously with degeneration (Ferenczy 1976a, Ludwig \& Spornitz 1991). Re-epithelialization begins on D2 during active menstruation and is complete by D5-6 (Ferenczy 1976a, Ludwig \& Spornitz 1991). On D6-7 (proliferative phase), substantial stromal proliferation begins (Ludwig \& Spornitz 1991), increasing the overall thickness of the endometrium from $1-4 \mathrm{~mm}$ to 11 $\mathrm{mm}$ just prior to ovulation (Nalaboff et al. 2001). In addition to stromal growth, both GE and LE proliferation continues along with angiogenesis under $E_{2}$ stimulation. On approximately D14, ovulation occurs initiating the secretory phase. Cellular changes in this stage under $\mathrm{P}_{4}$ influence include epithelial differentiation, particularly GE, stromal cell decidualization and infiltration 
of immune cells (late secretory). Of importance is decidualization of perivascular stromal cells. Decidualization is the morphological and functional differentiation of stromal cells into decidual cells to provide support for an embryo. The process begins with a brief increase in mitotic activity of perivascular stromal cells around D22-23 (Gellersen \& Brosens 2014) resulting in minimal polyploidization $(\sim 1 \%$ of stromal cells) (Qi et al. 2015). This is followed by transition of stromal cells from elongated, fibroblastlike mesenchymal cells into rounded, secretory epithelial-like cells. Changes indicative of epitheliallike transformation include expression of E-cadherin and cytokeratin, increased cellular area and circularity, enlarged and rounded nuclei, dense membrane-bound secretory granules and cytoplasmic accumulation of glycogen and lipid droplets (Gellersen \& Brosens 2014, Pan-Castillo et al. 2018). Decidualization occurs in preparation for an embryo and is critical for establishment and maintenance of early pregnancy. Finally, at the end of the secretory phase, in the absence of pregnancy, endometrial shedding ensues and the menstrual cycle repeats.

The estrous cycle comprises four phases: proestrus, estrus, metestrus and diestrus. Proestrus and estrus correspond to the ovarian follicular phase and are dominated by $E_{2}$, whereas metestrus and diestrus are dominated by $\mathrm{P}_{4}$ and correspond to the luteal phase. In mice the cycle duration is $4-5$ days, and in contrast to the menstrual cycle, D1 begins on the day following ovulation which coincides with behavioral estrus (Bertolin \& Murphy 2014). LE proliferation is relatively comparable across the cycle however, apoptosis is significantly higher in metestrus (Wood et al. 2007) resulting in a two- to four-fold higher cell number in proestrus and estrus (Evans et al. 1990). Stromal cell proliferation is highest in estrus, with a moderate amount in the other three stages, and apoptosis is highest in metestrus. Interestingly, changes in the GE do not follow the same pattern as the LE. GE proliferation is lowest in estrus and highest in proestrus and metestrus, with low levels of apoptosis throughout the cycle except in estrus. Overall uterine width is positively correlated with $\mathrm{E}_{2}$ and negatively correlated with $\mathrm{P}_{4}$ (Wood et al. 2007). In the absence of copulation, the ovarian corpora lutea regress rapidly and the next cycle begins.

The menstrual and estrous cycles are both characterized by stages of differential cellular activity including proliferation, differentiation, degeneration and regeneration which are regulated by ovarian derived $E_{2}$ and $P_{4}$. However, a major distinction between the menstrual and estrous cycles is the extent of endometrial remodeling that occurs. The greatest amount of remodeling occurs during menstruation in which the functionalis is shed and expelled from the body thus requiring extensive regeneration of the endometrium. However, in estrous cycling species such as mice, the endometrium is not shed, rather the tissue goes through cycles of mild resorption and growth (Wood et al. 2007).

Regarding the myometrium, much less is known about the cellular changes that occur throughout the menstrual cycle. Up until the early 2000s, the myometrium was considered a quiescent tissue outside of pregnancy, composed predominantly of differentiated smooth muscle cells (Teixeira et al. 2008). However, the myometrium is a dynamic tissue, responsive to various stimuli including $\mathrm{E}_{2}, \mathrm{P}_{4}$ and a milieu of paracrine factors (Burroughs et al. 2000, Taniguchi et al. 2001, Liu et al. 2013). During the menstrual cycle, myometrial proliferation is greatest in the secretory phase, whereas there are low levels of relatively consistent apoptosis throughout (Wu et al. 2000). This shows that, although less than the endometrium, there is in fact cellular turnover in the myometrium across the menstrual cycle.

\section{Pregnancy remodeling and postpartum repair (species comparison)}

During pregnancy, embryo implantation, stromal cell decidualization and placentation are critically important events in human (and murine) pregnancy that result in a substantial amount of uterine remodeling. In human implantation, embryonic trophoblasts invade the endometrium in between adjoining uterine LE cells (intrusion) with the goal of degrading the basement membrane and contacting the underlying stroma (Bischof \& Campana 1996). Comparatively in mice, the LE is also displaced by intrusion, as well as protrusion and entosis by trophoblasts. Additionally, LE opposite the invading trophoblast undergoes apoptosis ( $\mathrm{Li}$ et al. 2015). In women, stromal cell decidualization expands beyond the perivascular stromal cells that differentiated in the secretory phase of the menstrual cycle, to those adjacent to the embryo (reviewed in: Abrahamsohn \& Zorn 1993, Ramathal et al. 2010). In mice, decidualization does not occur during the estrous cycle and is therefore only initiated by an implanting embryo. Trophoblast cells continue to invade the decidualized stroma to the myometrium and remodel uterine spiral arteries, which is critical for formation of the placenta. As pregnancy progresses, in women in particular, the uterus increases in weight approximately 24 -fold, which is largely attributed to expansion of the myometrium by hyperplasia and hypertrophy (Johansson 1984). The human hemochorial placenta represents the most intimate association between the fetal membranes and maternal circulation and as such is also the most invasive form of placentation and involves substantial uterine remodeling (reviewed in: Rosenfeld 2007, Senger 2012). Mice also have a hemochorial placenta, however, major anatomical differences with the human placenta include: (1) trophoblast invasion stops at the myometrium in mice but continues into the muscle in women, (2) labyrinth (mouse) vs chorionic villi (human) structure and (3) 
number of trophoblast cell layers: monochorial (human) vs trichorial (mouse) (Schmidt et al. 2015). Following parturition and expulsion of the placenta in both species, the uterus exists in a degenerated state and all cellular components of the endometrium and myometrium are remodeled and/or repaired. Similar to menstrual regeneration, re-epithelialization of the endometrium precedes stromal expansion. This is likely because in the degenerated state, the endometrium is essentially an extensive wound and rapid re-epithelialization is needed to prevent infection. Historical observations in women show that the epithelium covers the nonplacental site of the endometrium by D7 postpartum and re-epithelialization of the entire endometrium is complete by approximately D14 (Sharman 1953). This is then followed by stromal expansion. In mice, the majority of information on endometrial repair comes from induced decidualization models (also termed menses-like models, described in detail subsequent). Similar to humans, epithelialization commences first within $24 \mathrm{~h}$ after the initiation of decidual breakdown/ shedding and is proceeded by stromal expansion (Brasted et al. 2003). Repair is complete within $48 \mathrm{~h}$. The myometrium having expanded several-fold due to cellular hyperplasia and hypertrophy, regresses to near its pre-gravid size, which is thought to include apoptosis, proliferation (Shynlova et al. 2009) and autophagy (Hsu et al. 2014) based on mouse studies. Uterine involution following parturition occurs relatively quickly allowing the uterus to be receptive to another embryo in 40-45 days in women and 3-4 days in mice.

Menstrual and postpartum uterine involution, specifically regeneration of lost or terminally differentiated cells (epithelial, stromal, myometrial), is highly dynamic and poorly understood. Proposed mechanisms of uterine regeneration include: (1) replication of residual GE and LE cells that escaped desquamation; (2) epithelial, stromal and myometrial stem cells; (3) mesenchymal-epithelial transition (MET) of stromal cells; and (4) infiltration and differentiation of bone marrow (BM)-derived cells into endometrial stromal and epithelial cells (Fig. 1C).

\section{Evidence for uterine stem cells and their role in involution}

Adult stem cells play an important role in tissue homeostasis and regeneration in many tissues (Blanpain \& Fuchs 2009, Biteau et al. 2011). Stem cells have the unique ability to self-renew, generate lineage-specific daughter cells, maintain long-term proliferative capacity and restore function to damaged tissue. They are also relatively quiescent compared to more lineage committed cells. Common methods used to enrich putative stem cells (Fig. 2) include expression of stem cell markers (Table 1), Hoechst dye exclusion (side population (SP) analysis) and label retention (Bianco et al. 2008, Vemuri et al. 2011). These putative stem cells must then be tested in a series of in vitro (colony/spheroid formation, lineage differentiation, long-term proliferation) and in vivo (lineage tracing, label retention) experiments to assess their stem cell qualities, the 'gold standard' of which is engraftment into the tissue of origin (i.e. orthotopic transplantation) and restoration of function to damaged tissue (van Os et al. 2004, Garry et al. 2009). Subsequent are discussions of the current evidence in support of the presence of uterine stem cells in women (summarized in Table 1). Following that are sections that describe mouse models used to further assess putative stem cells in uterine involution.

\section{Human endometrial mesenchymal stem cells (eMSCs)}

The first report of putative eMSCs (i.e. stromal stem cells) was published in 2004 (Chan et al. 2004). Using in vitro colony formation, distinct small and large colonies were observed that formed from single human endometrial stromal cells plated at a density of 300 cells $/ \mathrm{cm}^{2}$ (Chan et al. 2004). An average of $1.25 \%$ of stromal cells formed colonies with significantly greater colony forming efficiency (CE) of small colonies $(1.23 \%)$ compared to large $(0.02 \%)$. Although more small colonies formed on initial seeding (Chan et al. 2004), large colonies had greater serial propagation/cloning potential (Gargett et al. 2009). This suggests that small colonies may represent more differentiated transit amplifying (TA) cells with limited propagation potential whereas large colonies may be enriched for stem/progenitor cells. Clonogenic stromal cells were further characterized and enriched for using surface markers including melanoma cell adhesion molecule (MCAM; CD146), platelet-derived growth factor receptor-beta (PDGFR $\beta$; CD140b) (Schwab \& Gargett 2007, Schwab et al. 2008) and sushi domain containing 2 (SUSD2; clone W5C5) (Masuda et al. 2012). The osteogenic, myogenic, chondrogenic and adipogenic lineage differentiation of colony forming $\mathrm{CD} 146^{+} \mathrm{CD} 140 \mathrm{~b}^{+}$, and SUSD2 ${ }^{+}$cells was also shown (Schwab \& Gargett 2007, Dimitrov et al. 2008, Schwab et al. 2008, Gargett et al. 2009, Schuring et al. 2011, Masuda et al. 2012, Spitzer et al. 2012, Fayazi et al. 2015). Further, CD $146^{+}$CD $140 b^{+}$ and SUSD2 ${ }^{+}$cells were both located in the perivascular space (Cousins et al. 2018), which is a proposed MSC niche in multiple organs (Crisan et al. 2008). There was some overlap in expression of CD146/CD140b with SUSD2 (Masuda et al. 2012), however it is unclear if these markers identify the same or different populations of stem/progenitor-like cells.

Hoechst dye exclusion was used to obtain side population (SP) cells that were enriched for stem-like cells (Cervello et al. 2010). This cell-sorting procedure exploits the propensity of stem cells to efflux Hoechst dye because of relative overexpression of ATP transporters (Goodell et al. 1996). SP cells could form colonies 

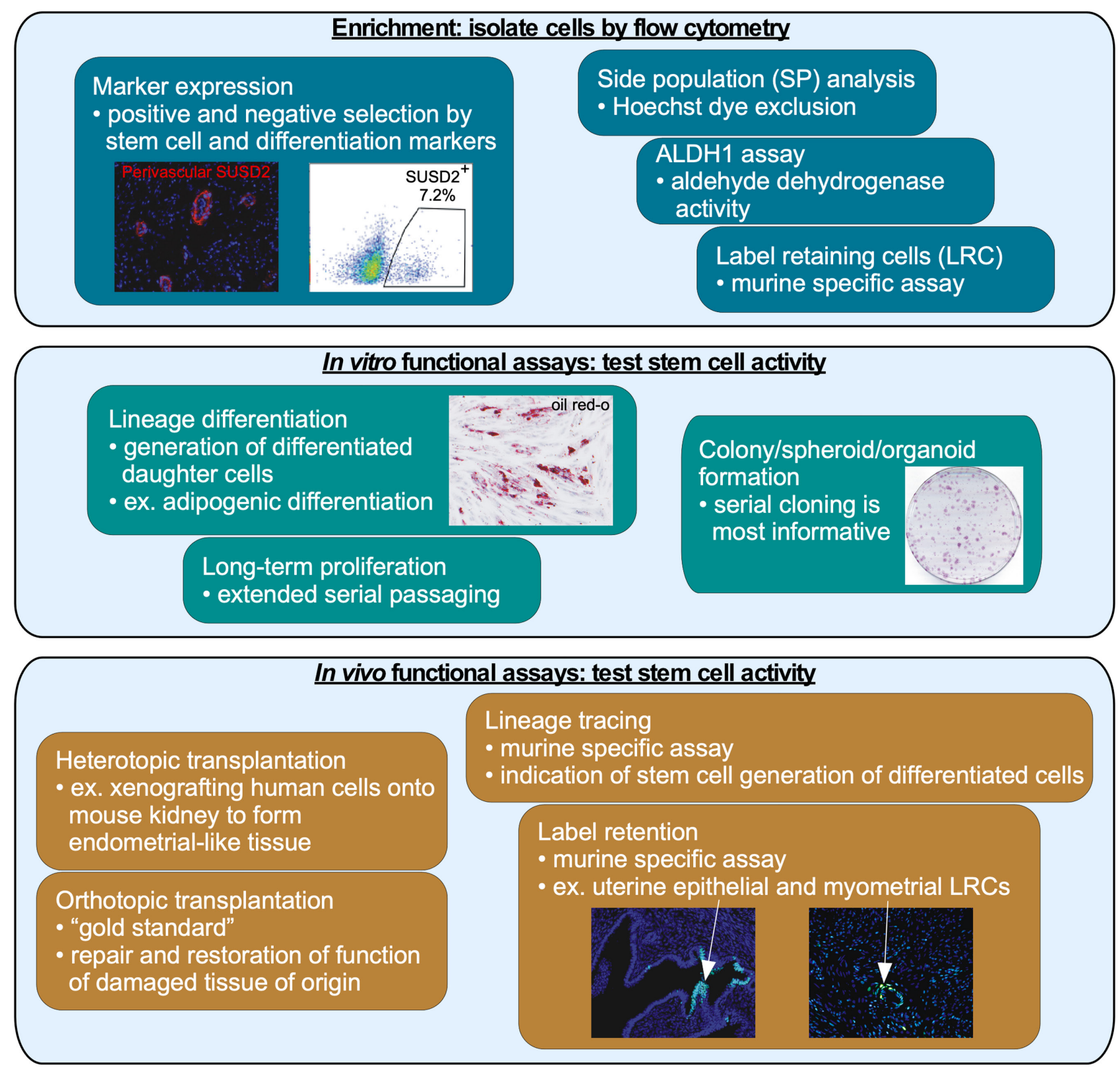

Figure 2 Diagram of common stem cell assays. Cells are typically isolated by various flow cytometry techniques to enrich for putative stem cells. The isolated cells are then tested for stem cell function in using in vitro and in vivo assays.

and differentiate in vitro and expressed various stem cell markers. Unfortunately, this method poses some caveats. First, Hoechst dye is cytotoxic and can impact downstream assays making results difficult to interpret. Second, the SP, although enriched for stem-like cells, is a heterogenous population. It may contain stromal, epithelial and endothelial stem-like cells. Therefore, purifying each cell type requires additional methods such as surface marker selection, which is often not performed.

In 2007, a mouse xenograft model was developed using human cells to study endometrial function (Masuda et al. 2007). Following injection of dissociated human endometrial cells under the renal capsule of immunodeficient mice and hormone treatment, endometrial-like tissue was formed that comprised of stroma and glands. Progesterone receptor (PGR) was upregulated upon $\mathrm{E}_{2}$ treatment and the stroma expressed the decidual marker prolactin (PRL) with combination of $E_{2}$ and $P_{4}$ treatment. Moreover, menstrual-like changes could be induced with cyclic administration of $E_{2}+P_{4}$ followed by $\mathrm{P}_{4}$ withdrawal. A hemorrhagic cyst was formed and there appeared to be epithelial and stromal cell shedding. This xenograft model has since been used as an in vivo stem cell assay to assess endometrial reconstitution by putative stem cells including SUSD2 ${ }^{+}$ 
Table 1 Summary of proposed markers used to identify putative uterine stem cells in human and mouse.

\begin{tabular}{|c|c|}
\hline Stem cell/ proposed markers & Reference \\
\hline \multicolumn{2}{|l|}{ Human } \\
\hline \multicolumn{2}{|l|}{ eEpScs } \\
\hline SSEA-1 & Valentijn et al. (2013) \\
\hline $\mathrm{N}$-cadherin & Nguyen et al. (2017) \\
\hline$\beta$-catenin, SOX9 & Nguyen et al. (2012, 2017), Tempest et al. (2018) \\
\hline LGR5 & Gil-Sanchis et al. (2013) \\
\hline \multicolumn{2}{|l|}{ myoMSCs } \\
\hline OCT4 & Ono et al. (2010) \\
\hline CD44, Stro-1 & Mas et al. (2015) \\
\hline CD140b, CD146, SUSD2 & Patterson et al. (2020) \\
\hline CD34, CD49f & Ono et al. (2015) \\
\hline \multicolumn{2}{|l|}{ eMSCs } \\
\hline MCAM (CD146), PDGFRß (CD140b) & Schwab \& Gargett (2007), Schwab et al. (2008) \\
\hline SUSD2 (clone W5C5) & Masuda et al. (2012) \\
\hline \multicolumn{2}{|l|}{ MenSCs } \\
\hline OCT4 & Meng et al. (2007), Nikoo et al. (2014), Patel et al. (2008) \\
\hline SOX2, Nanog & Liu et al. (2018), Sun et al. (2019) \\
\hline $\mathrm{C}-\mathrm{MyC}$ & Liu et al. (2018) \\
\hline SSEA-4 & Liu et al. (2018), Patel et al. (2008), Rossignoli et al. (2013), Sun et al. (2019) \\
\hline \multicolumn{2}{|r|}{ 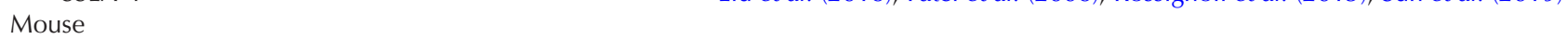 } \\
\hline \multicolumn{2}{|l|}{ eEpScs } \\
\hline AXIN2 & Syed et al. (2020) \\
\hline $\mathrm{CD} 44$ & Janzen et al. (2013) \\
\hline mTert & Cousins et al. (2019), Deane et al. (2016) \\
\hline LGR5 & Seishima et al. (2019) \\
\hline \multicolumn{2}{|l|}{ myoMSCs } \\
\hline OCT4,CD44 & Brakta et al. (2018), Mas et al. (2017)* \\
\hline Stro-1 & Mas et al. $(2017)^{*}$ \\
\hline CD140b, CD146 & Patterson et al. (2018) \\
\hline
\end{tabular}

*Reference shows proposed markers also found in rat model. eEpSCs, endometrial epithelial stem cells; eMSCs, endometrial mesenchymal stem cells; MenSCs, menstrual blood stem cells; myoMSCs, myometrial mesenchymal stem cells.

(Masuda et al. 2012) and SP enriched (Cervello et al. 2010, 2011, Masuda et al. 2010, Miyazaki et al. 2012) cells. However, it has not been used to study putative stem cells in menstrual repair. Although this renal-graft model can be used to provide valuable information about endometrial cell activity, to date, the 'gold standard' stem cell assay, which is transplantation into the tissue of origin (i.e. the endometrium), has not been performed. Transplantation of putative stem cells into the endometrium is necessary to determine their ability to contribute to endometrial function, including derivation of endometrial specific daughter cells that function in decidualization, embryo implantation and postpartum regeneration/repair.

Regarding the characteristics of putative eMSCs across the menstrual cycle, there do not appear to be significant differences in colony forming efficiency (Schwab et al. 2005, 2008) or expression of CD146 and CD140b (Schwab \& Gargett 2007) based on cycle stage. These results are not surprising considering that putative eMSCs express relatively low levels of estrogen receptor alpha (ESR1) and progesterone receptor (PGR). Therefore, regulation of these cells is likely through paracrine signaling by the niche rather than direct hormone action. Interestingly, although $\mathrm{E}_{2}$ is required for epithelial proliferation during the proliferative phase of the cycle, re-epithelialization during menstruation occurs at a time of relatively low $E_{2}$ levels (Ferenczy $1976 a, b$ ). Additionally, it was demonstrated that endometrial regeneration occurred following menstruation in human endometrial explants in ovariectomized mice in the absence of exogenous hormones (Matsuura-Sawada et al. 2005).

\section{Human menstrual blood stem cells (MenSC)}

Originally termed endometrial regenerative cells (ERC), putative menstrual blood-derived stem cells (MenSCs) were first observed in 2007 (Meng et al. 2007). Found to be derived from shed deciduous endometrial tissue (Rossignoli et al. 2013, Liu et al. 2018), these cells displayed the spindle-like morphology characteristic of fibroblasts (Mou et al. 2013, Rossignoli et al. 2013, Du et al. 2016, Faramarzi et al. 2016, Liu et al. 2018, Zheng et al. 2018). Through flow cytometry and immunofluorescence, it was demonstrated that putative MenSCs expresses various MSC markers but do not express hematopoietic, endothelial or immune activation markers (Patel et al. 2008, Mou et al. 2013, Rossignoli et al. 2013, Nikoo et al. 2014, Du et al. 2016, Faramarzi 
et al. 2016, Ren et al. 2016, Liu et al. 2018, Zheng et al. 2018, Sun et al. 2019). Although epithelial cells are shed along with mesenchymal cells, an epithelial stemlike population has not been isolated from menstrual blood. Reports show variable expression of pluripotency markers like OCT4, SOX2, Nanog, c-MyC and SSEA-4 by putative MenSCs (Meng et al. 2007, Patel et al. 2008, Rossignoli et al. 2013, Nikoo et al. 2014, Liu et al. 2018, Sun et al. 2019), with expression of SSEA-4 showing some of the greatest discrepancies between labs. This suggests a heterogeneous population of putative MenSCs, which requires further refinement.

Putative MenSCs have high proliferative capacity with no abnormalities identified by karyotyping following long-term passaging, thus indicating low mutagenesis (Meng et al. 2007, Patel et al. 2008, Rossignoli et al. 2013, Liu et al. 2018, Zheng et al. 2018). Interestingly, putative MenSCs have a higher CE ( 14\%) (Rossignoli et al. 2013) compared to reports of putative eMSCs. This may indicate that menstrual blood contains a mixture of stem, progenitor and transit amplifying cells which are all capable of forming primary colonies. Serial cloning may refine this population and give a more accurate estimation of stem cells. Many studies have demonstrated the in vitro capacity of putative MenSCs to differentiate into a variety of cell lineages: adipogenic, osteogenic, chondrogenic, neurogenic, cardiogenic, hepatogenic, pancreatogenic, myogenic, endothelia and pulmonary epithelia (Meng et al. 2007, Patel et al. 2008, Mou et al. 2013, Rossignoli et al. 2013, Du et al. 2016, Ren et al. 2016, Liu et al. 2018, Sun et al. 2019). Putative MenSCs also reformed endometrial-like tissue after s.c. grafting in immunocompromised mice and responded to hormone treatment as seen by expression of ESR1 and PGR (Zheng et al. 2018). When injected in the tail vein of immunocompromised mice, putative MenSCs tended to localize to the liver, lung and spleen and were not tumorigenic (Liu et al. 2018). Because MenSCs can reside in the liver following tail vein injection, evaluating their ability to regenerate hepatic tissue using a hepatogenic lineage seems promising. Indeed, transplantation of MenSC-derived hepatocytelike cells following $2 / 3$ partial hepatectomy in mice showed partial restoration of liver function (Mou et al. 2013). Therefore, providing the ease of collection and multi-lineage differentiation, researchers are beginning to realize the capabilities and uses of this putative stem cell population in regenerative medicine. Although these cells show promising therapeutic potential, more research is needed to fully characterize them and assess their regenerative capabilities.

\section{Human endometrial epithelial stem cells (eEpSC)}

Studies suggest the existence of endometrial epithelial stem cells (eEpSC) on the basis of in vitro colony formation, differentiation and long-term proliferation (Chan et al.
2004, Kato et al. 2007, Gargett et al. 2009, Nguyen et al. 2017) and in vivo reconstitution of endometrial epithelial-like tissue using the mouse renal-graft model (Masuda et al. 2007, Cervello et al. 2010, Miyazaki et al. 2012, Janzen et al. 2013). Uniquely, epithelial cells are capable of forming 3D colonies, termed spheroids or organoids. Organoids can be generated from individual epithelial cells and differentiate into the two primary endometrial cell types, ciliated and secretory (Boretto et al. 2017, Turco et al. 2017). Singlecell sequencing of endometrial epithelial organoids revealed a putative stem cell population (Fitzgerald et al. 2019). This population was the most predominant of all cell types when cultured in the absence of hormones. Upon hormone treatment, the presumptive stem-like population decreased and differentiated cell types increased. This may reveal a stem cell maintenance condition in hormone-free medium and differentiation of stem-like cells upon hormone induction. Whether this is an effect of culture or mimics in vivo regulation, remains to be determined. Interestingly, the proportion of cells expressing putative stem cell markers, in vivo, appeared to be higher in the hormone-deplete, post-menopausal endometrium compared to pre-menopausal (Valentijn et al. 2013, Nguyen et al. 2017). Together, these data may indicate that putative eEpSCs are more abundant in the absence of ovarian hormones and differentiate with hormone stimulus.

To date, there is no consensus on markers of putative eEpSCs, which has hindered further characterization and functional assessment of these cells. Proposed markers include the surface proteins SSEA-1 (Valentijn et al. 2013), N-cadherin (Nguyen et al. 2017), and LGR5 (GilSanchis et al. 2013, Cervello et al. 2017, Tempest et al. 2018) and the transcription factors $\beta$-catenin and SOX9 (Nguyen et al. 2012, Valentijn et al. 2013, Nguyen et al. 2017, Tempest et al. 2018). N-Cadherin ${ }^{+}$and SSEA-1 ${ }^{+}$ cells were predominantly located in the basalis layer and showed higher in vitro CE and spheroid formation, respectively, compared to negative cells (Valentijn et al. 2013, Nguyen et al. 2017). SSEA1 ${ }^{+}$cells had reduced expression of ESR1 and PGR mRNA compared to SSEA1 ${ }^{-}$cells, whereas most $\mathrm{N}$-cadherin ${ }^{+}$cells appeared to express ESR1 by immunofluorescence. SSEA $1^{+}$cells expressed SOX9 but $\mathrm{N}$-cadherin ${ }^{+}$cells rarely did and co-expression of SSEA1 and $\mathrm{N}$-cadherin was infrequent. These reports suggest two distinct populations of cells with in vitro stem/progenitor activity that may be indicative of cells at different stages of differentiation. LGR5, a known intestinal epithelial stem cell marker, was also investigated as an eEpSC marker. By IHC, LGR5 was expressed in random epithelial, stromal and perivascular cells (Gil-Sanchis et al. 2013) but by in situ hybridization was localized exclusively to the epithelium in a cycle-dependent manner (Tempest et al. 2018). When isolated and characterized, $\mathrm{LGR}^{+}$cells did not reconstruct endometrial-like tissue but rather 
had a phenotype more consistent with hematopoieticderived cells (Cervello et al. 2017). Therefore, LGR5 is unlikely to be a useful eEpSC marker in women. Telomerase activity (Valentijn et al. 2015) and SP analysis (Cervello et al. 2010, Masuda et al. 2010) also revealed putative eEpSCs based on CE and spheroid formation, and in vivo epithelium reconstruction in mouse renal or s.c. xenografts were used to assess stem-like activity in endometrial epithelium. However, as with putative eMSCs, epithelial cells have not been transplanted into the endometrium to more definitively assess stem cell characteristics and function.

\section{Human myometrial mesenchymal stem cells (myoMSC)}

The majority of studies on putative myoMSCs were conducted to identify stem/progenitor cells in fibroids, benign uterine smooth muscle tumors, compared with normal myometrium. Investigators have identified putative myoMSCs using many of the aforementioned methods including surface markers (Mas et al. 2015, Ono et al. 2015, Patterson et al. 2020) and SP analysis (Ono et al. 2007, Chang et al. 2010) followed by in vitro and in vivo stem cell assays. In the first report, SP analysis was used to enrich cells with osteogenic and adipogenic differentiation potential. Similar to eMSCs, these cells expressed low levels of ESR1 and PGR (Ono et al. 2007). More importantly, SP cells were engrafted into the myometrium of immunocompromised mice and appeared to differentiate into $\alpha$-SMA expressing myocytes. Although main population (MP) control cells were also able to engraft, they rarely expressed alphasmooth muscle actin $(\alpha-S M A)$, suggesting they did not contain lineage-differentiating stem/progenitor cells. To date, there is no consensus on markers to isolate putative myoMSCs. OCT4 (POUF51 gene) was expressed at relatively low levels in myometrium but was enriched for in the SP compared to the MP (Ono et al. 2010). Known as a pluripotency marker and expressed in embryonic stem cells, OCT4 may serve as a candidate marker of human MyoMSCs, however, this has yet to be tested. Other candidate markers include CD34/CD49f (Ono et al. 2015), CD44/Stro-1 (Mas et al. 2015) and CD140b/CD146 or SUSD2 (Patterson et al. 2020). Compared to control cells (CD34-CD49f-), CD 34 ${ }^{+} \mathrm{CD} 49^{+}$ myometrial cells were enriched for SP cells, formed more colonies and had greater osteogenic and adipogenic differentiation potential in vitro (Ono et al. 2015). Of note, $\mathrm{CD} 34^{+} \mathrm{CD} 49 \mathrm{f}^{+}$cells showed higher myometrial engraftment in immunocompromised mice, which was further enhanced with pregnancy. Stro $1^{+} \mathrm{CD} 44^{+}$cells expressed stem cell markers (e.g. OCT4 and NANOG) and showed adipogenic, osteogenic and chondrogenic differentiation compared to non-inducing conditions, however, they did not show significantly higher CE in vitro (Mas et al. 2015). Stro ${ }^{+}$CD $44^{+}$cells were engrafted under the renal capsule of immunocompromised mice and appeared to reconstitute some myometrial-like tissue based on actin and collagen expression, however, the contribution of human-derived cells was difficult to ascertain based on the cell tracker method used (Molday Ion Rhodamine B). Additionally, Stro ${ }^{+} \mathrm{CD} 44^{+}$ cells were not compared with control cells to determine differences in engraftment potential (Mas et al. 2015). Lastly, the markers used to enrich for putative eMSCs, CD146/CD140b co-expression or SUSD2, were shown to enrich for putative myoMSCs (Patterson et al. 2020). $\mathrm{CD} 146^{+} \mathrm{CD}_{140 \mathrm{~b}^{+} \text {and SUSD2 }}{ }^{+}$cells were located in the perivascular region similar to their location in the endometrium and had higher CE compared to control cells $\left(\mathrm{CD}_{146}{ }^{-} \mathrm{CD}_{140 b^{-}}\right.$or SUSD2-). Interestingly, $\mathrm{SUSD}^{+}$cells not only showed osteogenic and adipogenic differentiation but also appeared to undergo decidualization in vitro similar to endometrial stromal cells. This study suggests a possible common MSC for the endometrial stroma and myometrium (Patterson et al. 2020). However, further research is needed to assess the in vivo potential of SUSD2 ${ }^{+}$myometrial-derived cells to decidualize and contribute to uterine function in a stem/ progenitor cell capacity. Although there is compelling evidence for human myometrial stem/progenitor cells, there is inconsistency in isolation methods and a lack of in-depth studies to assess in vivo function of these cells.

\section{Murine models of uterine stem cells}

The literature discussed previously provides a solid foundation for the existence of uterine stem cells in women, however, technical and ethical constraints prevent in vivo studies of these cells in uterine involution. However, through the use of mouse models invaluable insight into uterine repair mechanisms has been garnered. Mice and humans share many similarities in pregnancy and postpartum uterine involution. In both species, embryo implantation is invasive, breeching the luminal epithelium, the stroma decidualizes and a hemochorial placenta is formed. Postpartum, the uterus undergoes extensive remodeling including stromal and epithelial regeneration and myometrial reduction. Mice do not menstruate; however, a menses-like mouse model was developed, which mimics the events of human menstruation (Finn \& Pope 1984, Brasted et al. 2003). Women menstruate, in part, because stromal cells near the spiral arteries decidualize in the late secretory phase of the menstrual cycle in preparation for pregnancy (Gellersen \& Brosens 2014). In mice, decidualization is induced by an implanting embryo. However, it can be induced by scratching the LE or infusing oil into the uterine lumen in a hormonally primed mouse. The scratch/oil causes epithelial cell death which initiates the decidual cascade in stromal cells. Upon removal of $\mathrm{P}_{4}$ stimulus, decidual tissue will breakdown which is manifested as menstrual-like shedding. Concomitant with decidual 
degeneration is endometrial repair/regeneration akin to menstrual shedding and regeneration. Using mouse models, intricate studies can be performed that provide more in-depth understanding of uterine involution in vivo. This includes additional stem cell assays such as label retention and lineage tracing, which are discussed subsequently and summarized in Fig. 2.

\section{Label-retention}

Stem cells divide relatively infrequently and therefore are proposed to retain label, such as bromodeoxyuridine (BrdU), while other more frequently dividing cells will lose label over time. Label-retaining cells (LRC) are then identified and assessed for additional stem cell properties. BrdU label retention has been used to identify slow cycling LRCs as potential stem/progenitor cells in mouse endometrium (Chan \& Gargett 2006, Cervello et al. 2007, Kaitu'u-Lino et al. 2010, 2012, Chan et al. 2012, Cao et al. 2015) and myometrium (Szotek et al. 2007). Stromal LRCs were localized primarily to the sub-luminal stroma, near blood vessels (perivascular) and at the stromal-myometrial boarder (analogous to the human basalis). This pattern remained consistent following pregnancy and postpartum uterine involution, although the percentage of LRCs was greatly reduced (Cao et al. 2015). Similarly, stromal LRCs were mostly perivascular and at the stromal-myometrial border during menses-like endometrial regeneration (Kaitu'u-Lino et al. 2012). The perivascular location of murine stromal LRCs corroborates data in human that putative eMSCs are also perivascular (Spitzer et al. 2012). Epithelial LRCs were predominantly found in the LE and to a lesser extent in the GE in nulliparous mice (Chan \& Gargett 2006b), however, label was rapidly diluted in the LE but retained in the GE during menseslike regeneration (Kaitu'u-Lino et al. 2010).

Using a transgenic mouse LRC model (H2Bj-GFP), LRCs were identified in the distal oviduct epithelium but not in the endometrium after labeling cells in adult mice for 7 days (Wang et al. 2012). The oviduct LRCs formed spheroids and based on differentiation in vitro, were proposed to be the stem/progenitor cells for the endometrial epithelium. In another study, LRCs were also found in the distal oviduct epithelium as well as the endocervical transition zone after embryonic thru prepubertal labeling (Patterson \& Pru 2013). However, these cells did not appear to participate in menseslike endometrial regeneration. Rather, when the label period was adjusted to the peripubertal period, longterm LRCs were found in the endometrial GE. These studies clearly illustrate how labeling under different physiological circumstances impacts which cells retain label. Recently, myometrial LRCs were characterized using the $\mathrm{H} 2 \mathrm{Bj}$-GFP transgenic labeling model (Patterson et al. 2018). The brightest LRCs expressed the putative human stromal and myometrial MSC markers, CD140b and CD146, were perivascular, and preferentially proliferated during menses-like uterine involution. Similar to putative human uterine stem cells, mouse uterine LRCs expressed little-to-no ESR1 and PGR (Chan \& Gargett 2006b, Chan et al. 2012, Wang et al. 2012, Patterson \& Pru 2013, Patterson et al. 2018).

An important caveat of LRC models is that cells undergoing terminal differentiation can also become labeled and if long-lived will be identified as LRCs. Therefore, follow up assays are critical to determine stem-cell activity of LRCs. To date, only one study has assessed the stem-like activity of epithelial LRCs by sphere formation (Wang et al. 2012). Stem cell activity of myometrial and stromal LRCs has yet to be assessed in vitro and no uterine LRCs have been transplanted to reconstitute uterine tissue in vivo.

\section{Lineage tracing and marker expression}

Using real-time, lineage tracing and ablation techniques, LGR5 was investigated as an eEpSC marker in mice (Seishima et al. 2019). LGR5 was expressed in the LE and budding GE during adenogenesis and became increasingly more restricted to the glands in prepubertal mice. In the adult, LGR5 was expressed sporadically in the LE and GE and almost exclusively during diestrus. The stem-like activity of $\mathrm{LGR}^{+}$cells was examined using a lineage tracing model (Lgr52A-CreERT2; R26-tdTomato) to indelibly label Lgr5 expressing cells and their progeny. When tracing was initiated during adenogenesis, labeling both LE and budding GE cells, LGR5 ${ }^{+}$cells contributed to growth and maintenance of the LE and GE in the adult. However, when tracing began after adenogenesis, labeling predominantly GE, $\mathrm{LGR}^{+}$cells only contributed to the GE in the adult but not the LE. Finally, if $\mathrm{LGR}^{+}$cells were traced beginning in the adult during diestrus, label was diminished by 2 weeks and undetectable after 1 year. These results suggest that prior to adenogenesis, LGR5 marks stem-like cells for both the LE and GE but shortly after, a delineation occurs and LGR5 only marks GE stem-like cells and in the adult does not serve as a marker for either. Importantly, ablation of $\mathrm{LGR5}^{+}$cells during adenogenesis resulted in a significant reduction in the number of glands formed and present in the adult, indicating their requirement for adenogenesis (Seishima et al. 2019). Because of the dynamic expression of LGR5 during postnatal adenogenesis, it would be interesting to see if LGR5 is upregulated during postpartum adenogenesis and re-epithelialization and could serve as a marker of stem cells in adult epithelial regeneration.

Two independent groups used an inducible, clonal, lineage-tracing model to evaluate the presence and activity of putative eEpSCs. By using an epithelial specific promoter, Krt19 (Jin 2019) or Pax8 (Syed et al. 2020), and low dose of the inducing agent, small 
subsets of LE and GE cells were labeled (fluorescent or LacZ) and their lineages traced over time. In both models, there was a progressive increase in the number of labeled cells throughout the epithelium suggesting they originated from individually labeled stem-like cells (Jin 2019, Syed et al. 2020). In a similar study, Confetti mice that expressed multiple fluorescent proteins stochastically were used to identify clones of epithelial cells that likely originated from individually labeled $\mathrm{Pax}^{+}$cells (Fu et al. 2020). These epithelial markers, however, are not restricted to putative stem cells but are also expressed in differentiated cells and in fact, abundantly throughout the endometrial epithelium (Fu et al. 2020, Syed et al. 2020). Therefore, more specific markers were used to assess clonal expansion of labeled cells as an indicator of stem cell activity. It has long been proposed that eEpSCs reside in endometrial glands (Gargett 2007). FOXA2 is a well-accepted GE marker (Jeong et al. 2010, Filant \& Spencer 2013) and AXIN2 (Syed et al. 2020) was shown to be restricted to the GE in the adult predominantly at the base of the glands nearest the myometrium. Again, using a low dose to induce label, a small proportion of GE cells expressing AXIN2 became labeled, allowing subsequent daughter cells to be tracked (Syed et al. 2020). The label appeared to spread from the base of the glands toward the lumen and after 3 months nearly all GE cells were labeled suggesting that individual $\mathrm{AXIN} 2^{+}$stem-like cells were responsible for GE expansion during the estrous cycle. However, the extent of contribution of $\mathrm{AXIN}^{+}$cells to the LE is unclear. Even though the LE proliferated every 3 days, labeled LE cells were not observed until after 3 months (Syed et al. 2020). One explanation could be that the low initial labeling of cells requires more time for labeled cells to reach the LE from the base of the GE and replace non-labeled cells. However, even with extensive initial labeling and after approximately 17 estrous cycles (2.5 months), there appeared to be littleto-no contribution to the LE. Additionally, following six pregnancies, there appeared to be only a few patches of LE cells derived from the labeled AXIN2+ GE cells. In agreeance with these results are those obtained from FOXA2-inducible lineage tracing, where FOXA2 ${ }^{+} \mathrm{GE}$ were reported to not contribute to the LE (Jin 2019), however, this model was not tested during postpartum repair. Although AXIN2+ GE cells may represent the stem/progenitor cell population for the GE, the identity of eEpSCs responsible for LE regeneration remains to be determined.

CD44 (Janzen et al. 2013) and mTert (mouse telomerase) (Deane et al. 2016, Cousins et al. 2019) have also been investigated as possible markers of endometrial stem/progenitor cells in mouse models. Using an in vivo renal-graft mouse model, hormonally deprived epithelial cells were serially transplanted in limiting dilution and as few as 100 transplanted epithelial cells were able to form gland-like structures (Janzen et al. 2013). These cells had increased expression of Cd44 and Axin2. CD44 and ITGA6, which marks the epithelial basement membrane, were used to isolate CD $44^{+} \mathrm{ITGA} 6^{+}$epithelial cells. Using serial xenografting, $0.92 \%$ of $\mathrm{CD}_{4} 4^{+} \mathrm{ITGA} 6^{+}$cells had regeneration potential compared to $0.03 \%$ of control cells (Janzen et al. 2013). In other studies, real-time expression of mTert was evaluated in the endometrium using mTert-GFP mice (Deane et al. 2016, Cousins et al. 2019). Expression was observed at very low percentages in several cell types within the endometrium, including immune, stromal, epithelial and endothelial (Deane et al. 2016). Consistent with other reports of putative stem/progenitor cells, no difference was found across the estrous cycle. Although some mTert-GFP ${ }^{+} \mathrm{GE}$ cells co-stained for CD44, some stromal and immune cells also expressed CD44, indicating lack of specificity. mTert-GFP ${ }^{+}$cells did not retain BrdU label or proliferate during endometrial maintenance (e.g. estrous turnover) (Deane et al. 2016). During menses-like repair in mice, the majority of mTert-GFP ${ }^{+}$cells were immune cells and $<0.1 \%$ of epithelial cells were mTert-GFP $^{+}$(Cousins et al. 2019). Very rare mTert-GFP ${ }^{+}$cells co-localized with the proliferation marker, $\mathrm{Ki}-67$. It was suggested that mTert may mark highly quiescent stem-like cells that upon activation undergo asymmetric cell division to generate highly proliferative transit amplifying cells (Cousins et al. 2019). It still remains to be determined to what extent $\mathrm{mTert}^{+}$endometrial cells contribute to postpartum uterine involution. CD44, in combination with Stro1 $\left(\mathrm{CD} 44^{+}\right.$Stro $\left.{ }^{+}\right)$, was also suggested as a marker for putative myoMSCs in rodent models. Rat CD44+Stro $1^{+}$ myometrial cells expressed the pluripotency marker Oct4 and low levels of ESR1 and PGR suggesting their undifferentiated state (Mas et al. 2017). Similarly, uteri from Oct4-GFP mice contained GFP myometrial cells that co-expressed CD44 (Brakta et al. 2018). Rodent cells expressing CD44/Stro1/OCT4 require further testing as putative myoMSCs including analysis of stem cell activity (e.g. colony formation and lineage differentiation in vitro and in vivo, etc.) and function in uterine involution.

The aforementioned studies (summarized in Table 1) have provided valuable insight into uterine repair using mouse models. But it is important to note some of the caveats. Label retention in itself does not definitively delineate stem cells from non-stem cells, and thus far, the stem cell activity of uterine LRCs has not been validated. Also, it is difficult to extrapolate the information learned from LRC studies to humans because there is no comparable assay that can be performed in women. Therefore, the LRC technique should be used as a steppingstone to further characterize uterine stem cells, such as a means to identify surface markers that may be useful in humans. However, it is cautioned that mouse and human markers may not correlate. LRG5 is a good example of a putative neonatal stem/progenitor marker in mice (Seishima et al. 2019) but not in adult women (Cervello et al. 2017). 


\section{Bone marrow-derived cells}

There are two potential sources of stem cells for the uterus: intra-uterine (endogenous uterine stem cells) and extra-uterine (Fig. 1). The previous sections were devoted to discussion of the evidence for endogenous uterine stem/progenitor cells in women and mice. In this section, a possible exogenous source will be discussed for both species.

In humans and mice, the presence of extra-uterine, bone marrow (BM)-derived cells was reported in the endometrium of transplant recipients (Taylor 2004, Du \& Taylor 2007, Ikoma et al. 2009, Morelli et al. 2013, GilSanchis et al. 2015, Tal et al. 2019). It is well-known that immune cells, which are derived from the BM, reside within all compartments of the uterus (Zhou et al. 2018, Lee et al. 2015), however, it is controversial whether these cells give rise to functional endometrial cells (Ong et al. 2018) or rather provide support to resident endometrial cells. Some reports suggest that nonimmune BM-derived cells, presumably MSCs, engraft in the endometrium and become stromal, GE and LE cells by transdifferentiation (Taylor 2004, Du \& Taylor 2007, Ikoma et al. 2009, Cervelló et al. 2012, Morelli et al. 2013, Gil-Sanchis et al. 2015, Tal et al. 2019). This theory is controversial and it is disputed if, and how, these BM-derived cells contribute to the endometrium in regards to regeneration, maintenance and function (Cervelló et al. 2012, Wolff et al. 2013, Ong et al. 2018).

The first report of BM-derived endometrial cells was conducted in 2004 (Taylor 2004). Uterine tissues were obtained from women who had previously received BM transplants, following radiation and chemotherapy (Taylor 2004). Donor-derived cells were identified in the endometrium of recipients and composed $0.2-48 \%$ of the epithelium and $0.3-52 \%$ of the stroma (Taylor 2004). In a similar study, $0.6-8.4 \%$ of epithelial cells and $8.2-9.8 \%$ of stromal cells were derived from donor BM (Ikoma et al. 2009). It is thought that BM-MSCs are the cells that engraft in the endometrium. However, Cervelló et al. (2012) concluded that engrafted BM-derived cells do not contribute to the endometrial SP and therefore are unlikely to contribute to the tissue in a stem cell capacity. Furthermore, clonal expansion of BM-derived cells, a hallmark of stem cell engraftment, has only been documented in the original study (Taylor 2004) and has not been replicated. In both women and mouse models, only sporadic BM-derived cells have been verified to express epithelial or stromal cell markers while also being negative for the pan-leukocyte marker, CD45 (Taylor 2004, Du \& Taylor 2007, Ikoma et al. 2009, Cervelló et al. 2012, Morelli et al. 2013, Gil-Sanchis et al. 2015). Thus, these studies concluded that although most BM-derived cells were immune cells, a few became epithelial or stromal cells. In contrast, another study used refined immunofluorescent and flow cytometry techniques in mice and reported that all engrafted BM-derived cells were immune cells based on marker expression and were therefore not epithelial or stromal cells (Ong et al. 2018). Another recent study used an inducible saturation labeling strategy in mice to investigate intra- vs extra-uterine sources of cells responsible for epithelial maintenance and regeneration postpartum. By labeling the majority of the epithelium $(\sim 90 \%)$, the contribution of nonlabeled extra-uterine cells was evaluated by calculating the percentage of labeled epithelial cells over time. The percentage of labeled epithelial cells remained relatively unchanged, suggesting that an un-labeled extra-uterine cell (e.g. BM) did not produce endometrial epithelial cells (Syed et al. 2020).

Studies on the function of purported BM-derived endometrial epithelial or stromal cells during pregnancy and uterine involution are lacking. BM-derived cells improved fertility in a mouse model of Asherman's syndrome (intra-uterine adhesions) (Alawadhi et al. 2014), but only rare BM-derived epithelial- and stromallike cells were identified ( 0.14 and $0.55 \%$, respectively). Although pregnancy rates were improved, their direct function in pregnancy was not assessed (Alawadhi et al. 2014). The only study that has investigated the role of BM-derived cells in pregnancy used tail vein BM transplantation following chemotherapy treatment (Tal et al. 2019). Depending on the day of pregnancy, the percentage of BM-derived cells in the endometrium ranged from 10 to $24 \%$, with $72-95 \%$ being CD $45^{+}$ leukocytes. Although other immune cell markers were used to assess different leukocyte populations that were $\mathrm{CD}^{2} 5^{-}$, they were not used in combination. Therefore, the population of immune cells may have been underrepresented. Moreover, no BM-derived epithelial cells were identified. Putative BM-derived stromal cells were assessed based on expression of PGR and DPRP (decidual-prolactin related protein). However, PGR may be expressed by various types of leukocytes (Shah et al. 2019), and BM-derived cells were concentrated in the mesometrial pole of the uterus whereas DPRP is typically concentrated in the anti-mesometrial side (Rasmussen et al. 1997, Candeloro \& Zorn 2007). The clonal expansion, longevity and contribution to subsequent pregnancies of these BM-derived putative stromal cells were not evaluated (Tal et al. 2019).

The evidence surrounding BM-derived cells in endometrial function is thus far circumstantial. BM-derived cells are being investigated for their ability to treat endometrial conditions including Asherman's syndrome in women (Santamaria et al. 2016, Singh et al. 2014). It will therefore be important to gain a more complete understanding of the existence and function of non-immune, BM-derived cells in the uterus.

\section{Mesenchymal-epithelial transition}

In the past decade, mesenchymal-epithelial transition (MET) has become an emerging hypothesis as a 
mechanism of endometrial re-epithelialization. Broadly, cellular transdifferentiation is the conversion of cells from one differentiated cell type to another, examples being MET or the reciprocal EMT (Lamouille et al. 2014). Of note, the occurrence of cellular transdifferentiation in the uterus was first described in embryonic development 60 years ago (Gruenwald 1959) and the MET hypothesis in adult re-epithelialization was first proposed in 1967 (Baggish et al. 1967). More recently using electron microscopy, the cellular and morphological changes during menstruation were evaluated (Garry et al. 2009). In the early stages of repair, single and small islands of new epithelial cells were observed that were frequently isolated from, and did not appear to arise from, protruding glandular stumps (Garry et al. 2009). These new cells were morphologically distinct from the more mature glandular cells; they appeared low and cuboidal in shape, smooth and lacked microvilli. As repair progressed, the new cells eventually fused with the more mature gland cells to form a continuous epithelial lining. The new epithelial cells, which formed in isolated singlets or small clusters, were suggested to originate from the stroma presumably by MET. Studies in mouse models also support the mechanism of MET in endometrial re-epithelialization (Huang et al. 2012, Patterson et al. 2013, Cousins et al. 2014, Yin et al. 2019). Mesenchyme-specific Cre driving promoters were used to induce reporter expression (e.g. EYFP or LacZ) to indelibly mark mesenchymal cells and their progeny. With this approach, reporter-positive epithelial cells were identified following postpartum and menseslike endometrial re-epithelialization suggesting that stromal cells underwent MET to produce epithelial cells (Huang et al. 2012, Patterson et al. 2013, Yin et al. 2019). Interestingly, presumptive mesenchymal/epithelial transitional cells (vimentin/cytokeratin co-expressing) were initially located at the stromal-myometrial boarder, a proposed mesenchymal stem cell niche for the stroma (Chan \& Gargett 2006a, Cervello et al. 2007) and moved toward the lumen as regeneration progressed (Patterson et al. 2013). This may suggest a role for stromal stem/ progenitor cells in MET. In support of this, mouse CD $34^{+} \mathrm{KLF}^{+}$putative eMSCs enhanced epithelial regeneration presumably through MET (Yin et al. 2019), and human $\mathrm{CD}_{146}{ }^{+}$putative eMSCs spontaneously differentiated into epithelial-like cells when cultured in a 3D-scaffold on top of myometrial cells (Fayazi et al. 2017). Collectively these studies provide evidence for MET, possibly by eMSCs, as a mechanism of endometrial re-epithelialization. However, this mechanism was recently challenged. Discussed previously, a saturation labeling technique was used in mice to investigate extrauterine BM cell contribution to endometrial epithelial turnover/regeneration. Because the percentage of labeled epithelial cells remained relatively unchanged, this not only suggested that un-labeled BM-derived cells did not contribute to the endometrial epithelium but also that unlabeled stromal cells also did not (Syed et al. 2020). Furthermore, MET was refuted on the suggestion that the Cre reporter mouse models used previously were not mesenchyme-specific (Ghosh et al. 2020). Clearly, more studies need to be conducted to confirm MET as a mechanism of re-epithelialization and determine if eMSCs are the source. It also remains to be determined if MET-derived (i.e. stromal-derived) epithelial cells are functional endometrial epithelial cells.

\section{Conclusions and future perspectives}

The uterus in women is a highly dynamic organ that withstands repeated physiological damage and repair events during the menstrual cycle and pregnancy/ postpartum. The extensive regeneration and rapid repair achieved suggests a role for stem/progenitor cells. The evidence for the existence of stem/progenitor cells is compelling however, the true identity, characteristics and functions of these putative cells have yet to be fully elucidated. This is due in part to the technical and ethical constraints surrounding human research. Although mouse models have provided invaluable clues into human uterine involution, caution must be placed on translation from mouse to human. Further, a suitable in vitro model that recapitulates the events of menstrual and postpartum involution, particularly cellular regeneration, has not been established.

A recent review nicely highlights the advances in development of in vitro models of the human endometrium (Fitzgerald et al. 2020). Readers are directed to this review for a detailed discussion; however, some important points are described here. First, improvements have been made in endometrial epithelial cell culture to more accurately mimic in vivo histoarchitecture. Of note, is incorporation of extracellular matrix components, typically using Matrigel, treatment with chemically defined media and formation of 3D organoids. These organoids are genetically stable, can be propagated long-term, express molecular signatures of LE and GE and are hormonally responsive (Boretto et al. 2017, Turco et al. 2017). Moreover, organoids can be derived from single cells suggesting the presence of stem cells, which is further supported by scRNA-Seq data revealing a potential stem/progenitor cell population (Fitzgerald et al. 2019). Beyond epithelial culture alone, attempts have been made to incorporate stromal cells, which is critical for recapitulating the in vivo endometrial environment. Advancements have been made using 3D porous scaffolds (Abbas et al. 2020), PEG hydrogels (Cook et al. 2017, Valdez et al. 2017) and scaffold-free, self-assembling environments (Wiwatpanit et al. 2020), to co-culture stromal and epithelial cells with varying degrees of success. Considerations include scaffold or gel components, matrix stiffness, ability of cells to properly orient and media conditions to support both 
cell types. Moreover, efforts to incorporate myometrial cells into these models have not been made, which will be important for a complete understanding of uterine involution. However, as progress continues in this field, it is anticipated that a suitable model will be developed that will facilitate research in human endometrial remodeling/repair and advance the identification and characterization of stem cells and their role in uterine involution.

\section{Declaration of interest}

The authors declare that there is no conflict of interest that could be perceived as prejudicing the impartiality of the research reported.

\section{Funding}

This research did not receive any specific grant from any funding agency in the public, commercial or not-for-profit sector.

\section{Author contribution statement}

A P conceptualized the manuscript. Y L S, M S, R W, D J and A $P$ all contributed to composition of the manuscript.

\section{References}

Abbas Y, Brunel LG, Hollinshead MS, Fernando RC, Gardner L, Duncan I, Moffett A, Best S, Turco MY, Burton GJ, et al. 2020 Generation of a threedimensional collagen scaffold-based model of the human endometrium. Interface Focus 10 20190079. (https://doi.org/10.1098/rsfs.2019.0079)

Abrahamsohn PA \& Zorn TMT 1993 Implantation and decidualization in rodents. Journal of Experimental Zoology 266 603-628. (https://doi. org/10.1002/jez.1402660610)

Alawadhi F, Du H, Cakmak H \& Taylor HS 2014 Bone marrow-derived stem cell (bmdsc) transplantation improves fertility in a murine model of Asherman's syndrome. PLOS ONE 9 e96662. (https://doi.org/10.1371/ journal.pone.0096662)

Baggish MS, Pauerstein CJ \& Woodruff JD 1967 Role of stroma in regeneration of endometrial epithelium. American Journal of Obstetrics \& Gynecology 99 459-465. (https://doi.org/10.1016/00029378(67)90291-8)

Bertolin K \& Murphy BD 2014 Reproductive tract changes during the mouse estrous cycle. In The Guide to Investigation of Mouse Pregnancy, pp. 85-94. Eds BA Croy, FJ Demayo \& SL Adamson. San Diego: Elsevier Science \& Technology. (https://doi.org/10.1016/B978-0-12-3944450.00007-2)

Bianco P, Robey PG \& Simmons PJ 2008 Mesenchymal stem cells: revisiting history, concepts, and assays. Cell Stem Cell 2 313-319. (https://doi. org/10.1016/j.stem.2008.03.002)

Bischof P \& Campana A 1996 A model for implantation of the human blastocyst and early placentation. Human Reproduction Update 2 262-270. (https://doi.org/10.1093/humupd/2.3.262)

Biteau B, Hochmuth CE \& Jasper H 2011 Maintaining tissue homeostasis: dynamic control of somatic stem cell activity. Cell Stem Cell 9 402-411. (https://doi.org/10.1016/j.stem.2011.10.004)

Blanpain C \& Fuchs E 2009 Epidermal homeostasis: a balancing act of stem cells in the skin. Nature Reviews. Molecular Cell Biology 10 207-217. (https://doi.org/10.1038/nrm2636)

Boretto M, Cox B, Noben M, Hendriks N, Fassbender A, Roose H, Amant F, Timmerman D, Tomassetti C, Vanhie A, et al. 2017 Development of organoids from mouse and human endometrium showing endometrial epithelium physiology and long-term expandability. Development 144 1775-1786. (https://doi.org/10.1242/dev.148478)

Brakta S, Mas A \& Al-Hendy A 2018 The ontogeny of myometrial stem cells in OCT4-GFP transgenic mouse model. Stem Cell Research \& Therapy 9 333. (https://doi.org/10.1186/s13287-018-1079-7)

Brasted M, White CA, Kennedy TG \& Salamonsen LA 2003 Mimicking the events of menstruation in the murine uterus. Biology of Reproduction 69 1273-1280. (https://doi.org/10.1095/biolreprod.103.016550)

Burroughs KD, Fuchs-Young R, Davis B \& Walker CL 2000 Altered hormonal responsiveness of proliferation and apoptosis during myometrial maturation and the development of uterine leiomyomas in the rat. Biology of Reproduction 63 1322-1330. (https://doi.org/10.1095/ biolreprod63.5.1322)

Candeloro L \& Zorn TM 2007 Granulated and non-granulated decidual prolactin-related protein-positive decidual cells in the pregnant mouse endometrium. American Journal of Reproductive Immunology $\mathbf{5 7}$ 122-132. (https://doi.org/10.1111/j.1600-0897.2006.00452.x)

Cao M, Chan RW \& Yeung WS 2015 Label-retaining stromal cells in mouse endometrium awaken for expansion and repair after parturition. Stem Cells \& Development 24 768-780. (https://doi.org/10.1089/scd.2014.0225)

Cervelló I, Gil-Sanchis C, Mas A, Delgado-Rosas F, Martinez-Conejero JA, Galan A, Martinez-Romero A, Martinez S, Navarro I, Ferro J, et al. 2010 Human endometrial side population cells exhibit genotypic, phenotypic and functional features of somatic stem cells. PLOS ONE 5 e10964. (https://doi.org/10.1371/journal.pone.0010964)

Cervelló I, Gil-Sanchis C, Mas A, Faus A, Sanz J, Moscardó F, Higueras G, Sanz MA, Pellicer A \& Simón C 2012 Bone marrow-derived cells from male donors do not contribute to the endometrial side population of the recipient. PLOS ONE 7 e30260. (https://doi.org/10.1371/journal. pone.0030260)

Cervello I, Gil-Sanchis C, Santamaria X, Faus A, Vallve-Juanico J, DiazGimeno P, Genolet O, Pellicer A \& Simon C 2017 Leucine-rich repeat-containing G-protein-coupled receptor 5-positive cells in the endometrial stem cell niche. Fertility \& Sterility 107 510-519.e3. (https:// doi.org/10.1016/j.fertnstert.2016.10.021)

Cervello I, Martinez-Conejero JA, Horcajadas JA, Pellicer A \& Simon C 2007 Identification, characterization and co-localization of labelretaining cell population in mouse endometrium with typical undifferentiated markers. Human Reproduction 22 45-51. (https://doi. org/10.1093/humrep/del332)

Cervello I, Mas A, Gil-Sanchis C, Peris L, Faus A, Saunders PT, Critchley HO \& Simon C 2011 Reconstruction of endometrium from human endometrial side population cell lines. PLOS ONE 6 e21221. (https://doi.org/10.1371/journal.pone.0021221)

Chan RW \& Gargett CE 2006a Identification of label-retaining cells in mouse endometrium. Stem Cells 24 1529-1538. (https://doi. org/10.1634/stemcells.2005-0411)

Chan RW, Kaitu'u-Lino T \& Gargett CE 2012 Role of label-retaining cells in estrogen-induced endometrial regeneration. Reproductive Sciences 19 102-114. (https://doi.org/10.1177/1933719111414207)

Chan RWS, Schwab KE \& Gargett CE 2004 Clonogenicity of human endometrial epithelial and stromal cells. Biology of Reproduction $\mathbf{7 0}$ 1738-1750. (https://doi.org/10.1095/biolreprod.103.024109)

Chang HL, Senaratne TN, Zhang L, Szotek PP, Stewart E, Dombkowski D, Preffer F, Donahoe PK \& Teixeira J 2010 Uterine leiomyomas exhibit fewer stem/progenitor cell characteristics when compared with corresponding normal myometrium. Reproductive Sciences 17 158-167. (https://doi.org/10.1177/1933719109348924)

Cook CD, Hill AS, Guo M, Stockdale L, Papps JP, Isaacson KB, Lauffenburger DA \& Griffith LG 2017 Local remodeling of synthetic extracellular matrix microenvironments by co-cultured endometrial epithelial and stromal cells enables long-term dynamic physiological function. Integrative Biology: Quantitative Biosciences from Nano to Macro 9 271-289. (https://doi.org/10.1039/c6ib00245e)

Cousins FL, Murray A, Esnal A, Gibson DA, Critchley HO \& Saunders PT 2014 Evidence from a mouse model that epithelial cell migration and mesenchymal-epithelial transition contribute to rapid restoration of uterine tissue integrity during menstruation. PLOS ONE 9 e86378. (https://doi.org/10.1371/journal.pone.0086378)

Cousins FL, O DF \& Gargett CE 2018 Endometrial stem/progenitor cells and their role in the pathogenesis of endometriosis. Best Practice \& 
Research. Clinical Obstetrics \& Gynaecology 50 27-38. (https://doi. org/10.1016/j.bpobgyn.2018.01.011)

Cousins FL, O DF, Ong YR, Breault DT, Deane JA \& Gargett CE 2019 Telomerase reverse transcriptase expression in mouse endometrium during reepithelialization and regeneration in a menses-like model. Stem Cells \& Development 28 1-12. (https://doi.org/10.1089/ scd.2018.0133)

Crisan M, Yap S, Casteilla L, Chen CW, Corselli M, Park TS, Andriolo G, Sun B, Zheng B, Zhang L, et al. 2008 A perivascular origin for mesenchymal stem cells in multiple human organs. Cell Stem Cell 3 301-313. (https://doi.org/10.1016/j.stem.2008.07.003)

Deane JA, Ong YR, Cain JE, Jayasekara WS, Tiwari A, Carlone DL, Watkins DN, Breault DT \& Gargett CE 2016 The mouse endometrium contains epithelial, endothelial and leucocyte populations expressing the stem cell marker telomerase reverse transcriptase. Molecular Human Reproduction 22 272-284. (https://doi.org/10.1093/molehr/gav076)

Dimitrov R, Timeva T, Kyurkchiev D, Stamenova M, Shterev A, Kostova P, Zlatkov V, Kehayov I \& Kyurkchiev S 2008 Characterization of clonogenic stromal cells isolated from human endometrium. Reproduction 135 551-558. (https://doi.org/10.1530/REP-07-0428)

Du H \& Taylor HS 2007 Contribution of bone marrow-derived stem cells to endometrium and endometriosis. Stem Cells 25 2082-2086. (https://doi. org/10.1634/stemcells.2006-0828)

Du X, Yuan Q, Qu Y, Zhou Y \& Bei J 2016 Endometrial mesenchymal stem cells isolated from menstrual blood by adherence. Stem Cells International 2016 3573846. (https://doi.org/10.1155/2016/3573846)

Evans GS, Gibson DF, Roberts SA, Hind TM \& Potten CS 1990 Proliferative changes in the genital tissue of female mice during the oestrous cycle. Cell \& Tissue Kinetics 23 619-635. (https://doi. org/10.1111/j.1365-2184.1990.tb01350.x)

Faramarzi H, Mehrabani D, Fard M, Akhavan M, Zare S, Bakhshalizadeh S, Manafi A, Kazemnejad S \& Shirazi R 2016 The potential of menstrual blood-derived stem cells in differentiation to epidermal lineage: a preliminary report. World Journal of Plastic Surgery 5 26-31.

Fayazi M, Salehnia M \& Ziaei S 2015 Differentiation of human CD146positive endometrial stem cells to adipogenic-, osteogenic-, neural progenitor-, and glial-like cells. In Vitro Cellular \& Developmental Biology. Animal 51 408-414. (https://doi.org/10.1007/s11626-0149842-2)

Fayazi M, Salehnia M \& Ziaei S 2017 In-vitro construction of endometriallike epithelium using CD146(+) mesenchymal cells derived from human endometrium. Reproductive Biomedicine Online 35 241-252. (https:// doi.org/10.1016/j.rbmo.2017.05.020)

Ferenczy A 1976a Studies on the cytodynamics of human endometrial regeneration. I. Scanning electron microscopy. American Journal of Obstetrics \& Gynecology 124 64-74. (https://doi.org/10.1016/00029378(76)90013-2)

Ferenczy A 1976b Studies on the cytodynamics of human endometrial regeneration. II. Transmission electron microscopy and histochemistry. American Journal of Obstetrics \& Gynecology 124 582-595. (https://doi. org/10.1016/0002-9378(76)90059-4)

Filant J \& Spencer TE 2013 Endometrial glands are essential for blastocyst implantation and decidualization in the mouse uterus. Biology of Reproduction 88 93. (https://doi.org/10.1095/biolreprod.113.107631)

Finn CA \& Pope M 1984 Vascular and cellular changes in the decidualized endometrium of the ovariectomized mouse following cessation of hormone treatment: A possible model for menstruation. Journal of Endocrinology 100 295-300. (https://doi.org/10.1677/joe.0.1000295)

Fitzgerald HC, Dhakal P, Behura SK, Schust DJ \& Spencer TE 2019 Self-renewing endometrial epithelial organoids of the human uterus. Proceedings of the National Academy of Sciences of the United States of America 116 23132-23142. (https://doi.org/10.1073/ pnas.1915389116)

Fitzgerald HC, Schust DJ \& Spencer TE 2020 In vitro models of the human endometrium: evolution and application for women's health. Biology of Reproduction In press (https://doi.org/10.1093/biolre/ioaa183)

Fu DJ, De Micheli AJ, Bidarimath M, Ellenson LH, Cosgrove BD, FleskenNikitin A \& Nikitin AY 2020 Cells expressing pax8 are the main source of homeostatic regeneration of adult mouse endometrial epithelium and give rise to serous endometrial carcinoma. Disease Models \& Mechanisms 13 dmm047035. (https://doi.org/10.1242/dmm.047035)
Gargett CE 2007 Uterine stem cells: what is the evidence? Human Reproduction Update 13 87-101. (https://doi.org/10.1093/humupd/ dml045)

Gargett CE, Schwab KE, Zillwood RM, Nguyen HPT \& Wu D 2009 Isolation and culture of epithelial progenitors and mesenchymal stem cells from human endometrium. Biology of Reproduction 80 1136-1145. (https:// doi.org/10.1095/biolreprod.108.075226)

Garry R, Hart R, Karthigasu KA \& Burke C 2009 A re-appraisal of the morphological changes within the endometrium during menstruation: a hysteroscopic, histological and scanning electron microscopic study. Human Reproduction 24 1393-1401. (https://doi.org/10.1093/humrep/ dep036)

Gellersen B \& Brosens JJ 2014 Cyclic decidualization of the human endometrium in reproductive health and failure. Endocrine Reviews 35 851-905. (https://doi.org/10.1210/er.2014-1045)

Ghosh A, Syed SM, Kumar M, Carpenter TJ, Teixeira JM, Houairia N, Negi S \& Tanwar PS 2020 In vivo cell fate tracing provides no evidence for mesenchymal to epithelial transition in adult fallopian tube and uterus. Cell Reports 31 107631. (https://doi.org/10.1016/j. celrep.2020.107631)

Gil-Sanchis C, Cervello I, Khurana S, Faus A, Verfaillie C \& Simon C 2015 Contribution of different bone marrow-derived cell types in endometrial regeneration using an irradiated murine model. Fertility \& Sterility $\mathbf{1 0 3}$ 1596-1605.e1. (https://doi.org/10.1016/j.fertnstert.2015.02.030)

Gil-Sanchis C, Cervello I, Mas A, Faus A, Pellicer A \& Simon C 2013 Leucine-rich repeat-containing G-protein-coupled receptor 5 (Igr5) as a putative human endometrial stem cell marker. Molecular Human Reproduction 19 407-414. (https://doi.org/10.1093/molehr/gat014)

Goodell MA, Brose K, Paradis G, Conner AS \& Mulligan RC 1996 Isolation and functional properties of murine hematopoietic stem cells that are replicating in vivo. Journal of Experimental Medicine 183 1797-1806. (https://doi.org/10.1084/jem.183.4.1797)

Gruenwald P 1959 Growth and development of the uterus: the relationship of epithelium to mesenchyme. Annals of the New York Academy of Sciences 75 436-440. (https://doi.org/10.1111/j.1749-6632.1959.tb44566.x)

Hsu KF, Pan HA, Hsu YY, Wu CM, Chung WJ \& Huang SC 2014 Enhanced myometrial autophagy in postpartum uterine involution. Taiwanese Journal of Obstetrics \& Gynecology 53 293-302. (https://doi. org/10.1016/j.tjog.2013.01.030)

Huang CC, Orvis GD GD, Wang Y \& Behringer RR 2012 Stromal-toepithelial transition during postpartum endometrial regeneration. PLOS ONE 7 e44285. (https://doi.org/10.1371/journal.pone.0044285)

Ikoma T, Kyo S, Maida Y, Ozaki S, Takakura M, Nakao S \& Inoue M 2009 Bone marrow-derived cells from male donors can compose endometrial glands in female transplant recipients. American Journal of Obstetrics \& Gynecology 201 608.e1-608.e8. (https://doi.org/10.1016/j. ajog.2009.07.026)

Jabbour HN, Kelly RW, Fraser HM \& Critchley HOD 2006 Endocrine regulation of menstruation. Endocrine Reviews 27 17-46. (https://doi. org/10.1210/er.2004-0021)

Janzen DM, Cheng D, Schafenacker AM, Paik DY, Goldstein AS, Witte ON, Jaroszewicz A, Pellegrini M \& Memarzadeh S 2013 Estrogen and progesterone together expand murine endometrial epithelial progenitor cells. Stem Cells 31 808-822. (https://doi.org/10.1002/stem.1337)

Jeong JW, Kwak I, Lee KY, Kim TH, Large MJ, Stewart CL, Kaestner KH, Lydon JP \& Demayo FJ 2010 Foxa2 is essential for mouse endometrial gland development and fertility. Biology of Reproduction 83 396-403. (https://doi.org/10.1095/biolreprod.109.083154)

Jin S 2019 Bipotent stem cells support the cyclical regeneration of endometrial epithelium of the murine uterus. Proceedings of the National Academy of Sciences of the United States of America 116 6848-6857. (https://doi.org/10.1073/pnas.1814597116)

Johansson B 1984 Different types of smooth muscle hypertrophy. Hypertension 6 III64-III68. (https://doi.org/10.1161/01.hyp.6.6_pt_2. iii64)

Kaitu'u-Lino TJ, Ye L \& Gargett CE 2010 Reepithelialization of the uterine surface arises from endometrial glands: evidence from a functional mouse model of breakdown and repair. Endocrinology 151 3386-3395. (https://doi.org/10.1210/en.2009-1334)

Kaitu'u-Lino TJ, Ye L, Salamonsen LA, Girling JE \& Gargett CE 2012 Identification of label-retaining perivascular cells in a mouse model 
of endometrial decidualization, breakdown, and repair. Biology of Reproduction 86 184. (https://doi.org/10.1095/biolreprod.112.099309)

Kato K, Yoshimoto M, Kato K, Adachi S, Yamayoshi A, Arima T, Asanoma K, Kyo S, Nakahata T \& Wake N 2007 Characterization of side-population cells in human normal endometrium. Human Reproduction 22 1214-1223. (https://doi.org/10.1093/humrep/del514)

Lamouille S, Xu J \& Derynck R 2014 Molecular mechanisms of epithelialmesenchymal transition. Nature Reviews. Molecular Cell Biology 15 178-196. (https://doi.org/10.1038/nrm3758)

Lee SK, Kim CJ, Kim DJ \& Kang JH 2015 Immune cells in the female reproductive tract. Immune Network 15 16-26. (https://doi.org/10.4110/ in.2015.15.1.16)

Li Y, Sun X \& Dey SK 2015 Entosis allows timely elimination of the luminal epithelial barrier for embryo implantation. Cell Reports 11 358-365. (https://doi.org/10.1016/j.celrep.2015.03.035)

Liu L, Li Y, Xie N, Shynlova O, Challis JR, Slater D, Lye S \& Dong X 2013 Proliferative action of the androgen receptor in human uterine myometrial cells--a key regulator for myometrium phenotype programming. Journal of Clinical Endocrinology \& Metabolism 98 218-227. (https://doi. org/10.1210/jc.2012-2451)

Liu Y, Niu R, Yang F, Yan Y, Liang S, Sun Y, Shen P \& Lin J 2018 Biological characteristics of human menstrual blood-derived endometrial stem cells. Journal of Cellular \& Molecular Medicine 22 1627-1639. (https:// doi.org/10.1111/jcmm.13437)

Ludwig H \& Spornitz UM 1991 Microarchitecture of the human endometrium by scanning electron microscopy: menstrual desquamation and remodeling. Annals of the New York Academy of Sciences 62228 46. (https://doi.org/10.1111/j.1749-6632.1991.tb37848.x)

Mas A, Nair S, Laknaur A, Simon C, Diamond MP \& Hendy A 2015 Stro-1/cd44 as putative human myometrial and fibroid stem cell markers. Fertility \& Sterility 104 225-34e3. (https://doi.org/10.1016/j. fertnstert.2015.04.021)

Mas A, Stone L, O'connor PM, Yang Q, Kleven D, Simon C, Walker CL \& Al-Hendy A 2017 Developmental exposure to endocrine disruptors expands murine myometrial stem cell compartment as a prerequisite to Leiomyoma tumorigenesis. Stem Cells 35 666-678. (https://doi. org/10.1002/stem.2519)

Masuda H, Anwar SS, Buhring HJ, Rao JR \& Gargett CE 2012 A novel marker of human endometrial mesenchymal stem-like cells. Cell Transplantation 21 2201-2214 (https://doi.org/10.3727/096368911X637362)

Masuda H, Maruyama T, Hiratsu E, Yamane J, Iwanami A, Nagashima T, Ono M, Miyoshi H, Okano HJ, Ito M, et al. 2007 Noninvasive and real-time assessment of reconstructed functional human endometrium in nod/scid/gamma c(null) immunodeficient mice. Proceedings of the National Academy of Sciences of the United States of America 104 1925-1930 (https://doi.org/10.1073/pnas.0604310104)

Masuda H, Matsuzaki Y, Hiratsu E, Ono M, Nagashima T, Kajitani T, Arase T, Oda H, Uchida H, Asada H, et al. 2010 Stem cell-like properties of the endometrial side population: implication in endometrial regeneration. PLOS ONE 5 e10387. (https://doi.org/10.1371/journal.pone.0010387)

Matsuura-Sawada R, Murakami T, Ozawa Y, Nabeshima H, Akahira J-I, Sato Y, Koyanagi Y, Ito M, Terada Y \& Okamura K 2005 Reproduction of menstrual changes in transplanted human endometrial tissue in immunodeficient mice. Human Reproduction 20 1477-1484. (https:// doi.org/10.1093/humrep/deh783)

Meng X, Ichim TE, Zhong J, Rogers A, Yin Z, Jackson J, Wang H, Ge W, Bogin V, Chan KW, et al. 2007 Endometrial regenerative cells: A novel stem cell population. Journal of Translational Medicine 5 57. (https://doi. org/10.1186/1479-5876-5-57)

Miyazaki K, Maruyama T, Masuda H, Yamasaki A, Uchida S, Oda H, Uchida H \& Yoshimura Y 2012 Stem cell-like differentiation potentials of endometrial side population cells as revealed by a newly developed in vivo endometrial stem cell assay. PLOS ONE 7 e50749. (https://doi. org/10.1371/journal.pone.0050749)

Morelli SS, Rameshwar P \& Goldsmith LT 2013 Experimental evidence for bone marrow as a source of nonhematopoietic endometrial stromal and epithelial compartment cells in a murine model. Biology of Reproduction 89 7. (https://doi.org/10.1095/biolreprod.113.107987)

Mou XZ, Lin J, Chen JY, Li YF, Wu XX, Xiang BY, Li CY, Ma JM \& Xiang C 2013 Menstrual blood-derived mesenchymal stem cells differentiate into functional hepatocyte-like cells. Journal of Zhejiang University. Science. B 14 961-972. (https://doi.org/10.1631/jzus.B1300081)
Nalaboff KM, Pellerito JS \& Ben-Levi E 2001 Imaging the endometrium: disease and normal variants1. RadioGraphics 21 1409-1424. (https:// doi.org/10.1148/radiographics.21.6.g01nv211409)

Nguyen HP, Sprung CN \& Gargett CE 2012 Differential expression of wnt signaling molecules between pre- and postmenopausal endometrial epithelial cells suggests a population of putative epithelial stem/progenitor cells reside in the basalis layer. Endocrinology 153 2870-2883. (https://doi.org/10.1210/en.2011-1839)

Nguyen HPT, Xiao L, Deane JA, Tan KS, Cousins FL, Masuda H, Sprung CN, Rosamilia A \& Gargett CE 2017 N-cadherin identifies human endometrial epithelial progenitor cells by in vitro stem cell assays. Human Reproduction 32 2254-2268. (https://doi.org/10.1093/humrep/dex289)

Nikoo S, Ebtekar M, Jeddi-Tehrani M, Shervin A, Bozorgmehr M, Vafaei S, Kazemnejad S \& Zarnani AH 2014 Menstrual blood-derived stromal stem cells from women with and without endometriosis reveal different phenotypic and functional characteristics. Molecular Human Reproduction 20 905-918. (https://doi.org/10.1093/molehr/gau044)

Ong YR, Cousins FL, Yang X, Mushafi AAAA, Breault DT, Gargett CE \& Deane JA 2018 Bone marrow stem cells do not contribute to endometrial cell lineages in chimeric mouse models. Stem Cells 36 91-102. (https:// doi.org/10.1002/stem.2706)

Ono $M$, Kajitani T, Uchida $H$, Arase T, Oda H, Nishikawa-Uchida S, Masuda H, Nagashima T, Yoshimura Y \& Maruyama T 2010 Oct4 expression in human uterine myometrial stem/progenitor cells. Human Reproduction 25 2059-2067. (https://doi.org/10.1093/humrep/deq163)

Ono M, Kajitani T, Uchida H, Arase T, Oda H, Uchida S, Ota K, Nagashima T, Masuda H, Miyazaki K, et al. 2015 CD34 and CD49f double-positive and lineage marker-negative cells isolated from human myometrium exhibit stem cell-like properties involved in pregnancyinduced uterine remodeling. Biology of Reproduction 93 37. (https://doi. org/10.1095/biolreprod.114.127126)

Ono M, Maruyama T, Masuda H, Kajitani T, Nagashima T, Arase T, Ito M, Ohta K, Uchida H, Asada H, et al. 2007 Side population in human uterine myometrium displays phenotypic and functional characteristics of myometrial stem cells. Proceedings of the National Academy of Sciences of the United States of America 104 18700-18705. (https://doi. org/10.1073/pnas.0704472104)

Pan-Castillo B, Gazze SA, Thomas S, Lucas C, Margarit L, Gonzalez D, Francis LW \& Conlan RS 2018 Morphophysical dynamics of human endometrial cells during decidualization. Nanomedicine: Nanotechnology, Biology, and Medicine 14 2235-2245. (https://doi. org/10.1016/j.nano.2018.07.004)

Patel AN, Park E, Kuzman M, Benetti F, Silva FJ \& Allickson JG 2008 Multipotent menstrual blood stromal stem cells: isolation, characterization, and differentiation. Cell Transplantation 17 303-311. (https://doi.org/10.3727/096368908784153922)

Patterson AL \& Pru JK 2013 Long-term label retaining cells localize to distinct regions within the female reproductive epithelium. Cell Cycle $\mathbf{1 2}$ 2888-2898. (https://doi.org/10.4161/cc.25917)

Patterson AL, George JW, Chatterjee A, Carpenter T, Wolfrum E, Pru JK \& Teixeira JM 2018 Label-retaining, putative mesenchymal stem cells contribute to murine myometrial repair during uterine involution. Stem Cells \& Development 27 1715-1728. (https://doi.org/10.1089/ scd.2018.0146)

Patterson AL, George JW, Chatterjee A, Carpenter TJ, Wolfrum E, Chesla DW \& Teixeira JM 2020 Putative human myometrial and fibroid stem-like cells have mesenchymal stem cell and endometrial stromal cell properties. Human Reproduction 35 44-57. (https://doi.org/10.1093/ humrep/dez247)

Patterson AL, Zhang L, Arango NA, Teixeira J \& Pru JK 2013 Mesenchymalto-epithelial transition contributes to endometrial regeneration following natural and artificial decidualization. Stem Cells \& Development 22 964-974. (https://doi.org/10.1089/scd.2012.0435)

Qi QR, Zhao XY, Zuo RJ, Wang TS, Gu XW, Liu JL \& Yang ZM 2015 Involvement of atypical transcription factor e2f8 in the polyploidization during mouse and human decidualization. Cell Cycle 14 1842-1858. (https://doi.org/10.1080/15384101.2015.1033593)

Ramathal CY, Bagchi IC, Taylor RN \& Bagchi MK 2010 Endometrial decidualization: of mice and men. Seminars in Reproductive Medicine 28 17-26. (https://doi.org/10.1055/s-0029-1242989)

Rasmussen CA, Orwig KE, Vellucci S \& Soares MJ 1997 Dual expression of prolactin-related protein in decidua and trophoblast tissues during 
pregnancy in rats. Biology of Reproduction 56 647-654. (https://doi. org/10.1095/biolreprod56.3.647)

Ren H, Sang Y, Zhang F, Liu Z, Qi N \& Chen Y 2016 Comparative analysis of human mesenchymal stem cells from umbilical cord, dental pulp, and menstrual blood as sources for cell therapy. Stem Cells International 2016 3516574. (https://doi.org/10.1155/2016/3516574)

Rosenfeld CS 2007 Introduction to comparative placentation. In Comparative Reproductive Biology. Eds. H Schatten \& GM ConstatinescuAmes, IA: Blackwell Publishing, pp. 263-319. (https://doi. org/10.1002/9780470390290.ch11)

Rossignoli F, Caselli A, Grisendi G, Piccinno S, Burns JS, Murgia A, Veronesi E, Loschi P, Masini C, Conte P, et al. 2013 Isolation, characterization, and transduction of endometrial decidual tissue multipotent mesenchymal stromal, stem cells from menstrual blood. BioMed Research International 2013 901821. (https://doi. org/10.1155/2013/901821)

Santamaria X, Cabanillas S, Cervello I, Arbona C, Raga F, Ferro J, Palmero J, Remohi J, Pellicer A \& Simon C 2016 Autologous cell therapy with CD133+ bone marrow-derived stem cells for refractory Asherman's syndrome and endometrial atrophy: A pilot cohort study. Human Reproduction 31 1087-1096. (https://doi.org/10.1093/humrep/dew042)

Schmidt A, Morales-Prieto DM, Pastuschek J, Frohlich K \& Markert UR 2015 Only humans have human placentas: molecular differences between mice and humans. Journal of Reproductive Immunology $\mathbf{1 0 8}$ 65-71. (https://doi.org/10.1016/j.jri.2015.03.001)

Schuring AN, Schulte N, Kelsch R, Ropke A, Kiesel L \& Gotte M 2011 Characterization of endometrial mesenchymal stem-like cells obtained by endometrial biopsy during routine diagnostics. Fertility and Sterility 95 423-426. (https://doi.org/10.1016/j.fertnstert.2010.08.035).

Schwab KE \& Gargett CE 2007 Co-expression of two perivascular cell markers isolates mesenchymal stem-like cells from human endometrium. Human Reproduction 22 2903-2911. (https://doi.org/10.1093/humrep/ dem265)

Schwab KE, Chan RW \& Gargett CE 2005 Putative stem cell activity of human endometrial epithelial and stromal cells during the menstrual cycle. Fertility and Sterility 84(Supplement 2) 1124-1130. (https://doi. org/10.1016/j.fertnstert.2005.02.056)

Schwab KE, Hutchinson P \& Gargett CE 2008 Identification of surface markers for prospective isolation of human endometrial stromal colony-forming cells. Human Reproduction 23 934-943. (https://doi. org/10.1093/humrep/den051)

Seishima R, Leung C, Yada S, Murad KBA, Tan LT, Hajamohideen A, Tan SH, Itoh H, Murakami K, Ishida Y, et al. 2019 Neonatal wnt-dependent Igr5 positive stem cells are essential for uterine gland development. Nature Communications 10 5378. (https://doi.org/10.1038/s41467-01913363-3)

Senger PL 2012 Pathways to Pregnancy and Parturition: Redmond, OR: Current Conceptions Incorp.

Shah NM, Lai PF, Imami N \& Johnson MR 2019 Progesterone-related immune modulation of pregnancy and labor. Frontiers in Endocrinology 10 198. (https://doi.org/10.3389/fendo.2019.00198)

Sharman A 1953 Post-partum regeneration of the human endometrium. Journal of Anatomy 87 1-10.

Shynlova O, Tsui P, Jaffer S \& Lye SJ 2009 Integration of endocrine and mechanical signals in the regulation of myometrial functions during pregnancy and labour. European Journal of Obstetrics, Gynecology, and Reproductive Biology 144(Supplement 1) S2-S10. (https://doi. org/10.1016/j.ejogrb.2009.02.044)

Singh N, Mohanty S, Seth T, Shankar M, Bhaskaran S \& Dharmendra S 2014 Autologous stem cell transplantation in refractory Asherman's syndrome: A novel cell based therapy. Journal of Human Reproductive Sciences 7 93-98. (https://doi.org/10.4103/0974-1208.138864)

Spitzer TL, Rojas A, Zelenko Z, Aghajanova L, Erikson DW, Barragan F, Meyer M, Tamaresis JS, Hamilton AE, Irwin JC, et al. 2012 Perivascular human endometrial mesenchymal stem cells express pathways relevant to self-renewal, lineage specification, and functional phenotype. Biology of Reproduction 86 58. (https://doi.org/10.1095/ biolreprod.111.095885)

Sun Y, Ren Y, Yang F, He Y, Liang S, Guan L, Cheng F, Liu Y \& Lin J 2019 High-yield isolation of menstrual blood-derived endometrial stem cells by direct red blood cell lysis treatment. Biology Open 8 bio038885. (https://doi.org/10.1242/bio.038885)
Syed SM, Kumar M, Ghosh A, Tomasetig F, Ali A, Whan RM, Alterman D \& Tanwar PS 2020 Endometrial axin2(+) cells drive epithelial homeostasis, regeneration, and cancer following oncogenic transformation. Cell Stem Cell 26 64-80 e13. (https://doi.org/10.1016/j.stem.2019.11.012)

Szotek PP, Chang HL, Zhang L, Preffer F, Dombkowski D, Donahoe PK \& Teixeira J 2007 Adult mouse myometrial label-retaining cells divide in response to gonadotropin stimulation. Stem Cells 25 1317-1325. (https://doi.org/10.1634/stemcells.2006-0204)

Tal R, Shaikh S, Pallavi P, Tal A, Lopez-Giraldez F, Lyu F, Fang YY, Chinchanikar S, Liu Y, Kliman HJ, et al. 2019 Adult bone marrow progenitors become decidual cells and contribute to embryo implantation and pregnancy. PLOS Biology 17 e3000421. (https://doi. org/10.1371/journal.pbio.3000421)

Taniguchi Y, Morita I, Kubota T, Murota S \& Aso T 2001 Human uterine myometrial smooth muscle cell proliferation and vascular endothelial growth-factor production in response to platelet-derived growth factor. Journal of Endocrinology 169 79-86. (https://doi.org/10.1677/ joe.0.1690079)

Taylor HS 2004 Endometrial cells derived from donor stem cells in bone marrow transplant recipients. JAMA 292 81-85. (https://doi.org/10.1001/ jama.292.1.81)

Teixeira J, Rueda BR \& Pru JK 2008 Uterine stem cells. In Stembook. Harvard Stem Cell Institute: Cambridge, MA, USA. (https://doi. org/10.3824/stembook.1.16.1)

Tempest N, Baker AM, Wright NA \& Hapangama DK 2018 Does human endometrial lgr5 gene expression suggest the existence of another hormonally regulated epithelial stem cell niche? Human Reproduction 33 1052-1062. (https://doi.org/10.1093/humrep/dey083)

Turco MY, Gardner L, Hughes J, Cindrova-Davies T, Gomez MJ, Farrell L, Hollinshead M, Marsh SGE, Brosens JJ, Critchley HO, et al. 2017 Longterm, hormone-responsive organoid cultures of human endometrium in a chemically defined medium. Nature Cell Biology 19 568-577. (https:// doi.org/10.1038/ncb3516)

Valdez J, Cook CD, Ahrens CC, Wang AJ, Brown A, Kumar M, Stockdale L, Rothenberg D, Renggli K, Gordon E, et al. 2017 On-demand dissolution of modular, synthetic extracellular matrix reveals local epithelial-stromal communication networks. Biomaterials 130 90-103. (https://doi. org/10.1016/j.biomaterials.2017.03.030)

Valentijn AJ, Palial K, Al-Lamee H, Tempest N, Drury J, Von Zglinicki T, Saretzki G, Murray P, Gargett CE \& Hapangama DK 2013 Ssea-1 isolates human endometrial basal glandular epithelial cells: phenotypic and functional characterization and implications in the pathogenesis of endometriosis. Human Reproduction 28 2695-2708. (https://doi. org/10.1093/humrep/det285)

Valentijn AJ, Saretzki G, Tempest N, Critchley HO \& Hapangama DK 2015 Human endometrial epithelial telomerase is important for epithelial proliferation and glandular formation with potential implications in endometriosis. Human Reproduction 30 2816-2828. (https://doi. org/10.1093/humrep/dev267)

Van Os R, Kamminga LM \& De Haan G 2004 Stem cell assays: something old, something new, something borrowed. Stem Cells 22 1181-1190. (https://doi.org/10.1634/stemcells.2004-0095)

Vemuri MC, Chase LG \& Rao MS 2011 Mesenchymal stem cell assays and applications. Methods in Molecular Biology 698 3-8. (https://doi. org/10.1007/978-1-60761-999-4_1)

Wang Y, Sacchetti A, Van Dijk MR, Van Der Zee M, Van Der Horst PH, Joosten R, Burger CW, Grootegoed JA, Blok LJ \& Fodde R 2012 Identification of quiescent, stem-like cells in the distal female reproductive tract. PLOS ONE 7 e40691 (https://doi.org/10.1371/ journal.pone.0040691)

Wiwatpanit T, Murphy AR, Lu Z, Urbanek M, Burdette JE, Woodruff TK \& Kim JJ 2020 Scaffold-free endometrial organoids respond to excess androgens associated with polycystic ovarian syndrome. Journal of Clinical Endocrinology \& Metabolism 105 769-780. (https://doi. org/10.1210/clinem/dgz100)

Wolff EF, Uchida N, Donahue RE, Metzger ME, Hsieh MM, Libfraind LL, Hill MJ \& Tisdale JF 2013 Peripheral blood stem cell transplants do not result in endometrial stromal engraftment. Fertility \& Sterility 99 526532.e2. (https://doi.org/10.1016/j.fertnstert.2012.09.045)

Wood GA, Fata JE, Watson KL \& Khokha R 2007 Circulating hormones and estrous stage predict cellular and stromal remodeling in murine uterus. Reproduction 133 1035-1044. (https://doi.org/10.1530/REP-06-0302) 
Wu X, Blanck A, Olovsson M, Moller B, Favini R \& Lindblom B 2000 Apoptosis, cellular proliferation and expression of p53 in human uterine leiomyomas and myometrium during the menstrual cycle and after menopause. Acta Obstetricia \& Gynecologica Scandinavica 79 397-404.

Yin M, Zhou HJ, Lin C, Long L, Yang X, Zhang H, Taylor H \& Min W 2019 CD34(+)klf4(+) stromal stem cells contribute to endometrial regeneration and repair. Cell Reports 27 2709-2724.e3. (https://doi.org/10.1016/j. celrep.2019.04.088)

Zheng SX, Wang J, Wang XL, Ali A, Wu LM \& Liu YS 2018 Feasibility analysis of treating severe intrauterine adhesions by transplanting menstrual blood-derived stem cells. International Journal of Molecular Medicine 41 2201-2212. (https://doi.org/10.3892/ijmm.2018.3415)
Zhou JZ, Way SS \& Chen K 2018 Immunology of the uterine and vaginal mucosae. Trends in Immunology 39 302-314. (https://doi.org/10.1016/j. it.2018.01.007)

Received 31 July 2020

First decision 10 September 2020

Revised manuscript received 14 December 2020

Accepted 12 January 2021 